\title{
FLAVONOIDS AND CARDIOVASCULAR RISK FACTORS: A REVIEW
}

\author{
A. Ahmed \\ Department of Life Sciences, University of Siena, Siena, Italy \\ E-mail: aa.biotechiub@gmail.com \\ Doi: 10.36118/pharmadvances.2021.15
}

\section{SUMMARY}

Several modifiable and non-modifiable risk factors are associated with incidence of cardiovascular diseases, the leading cause of death worldwide. A healthy diet, such as the Mediterranean diet, lowers the incidence of cardiovascular disease. Intake of flavonoids, a class of plant-derived polyphenols widely distributed in fruits, vegetables, tea, coffee, and wine, is the hallmark of the Mediterranean diet that has been associated with reduced cardiovascular risk factors. Several mechanisms underpin this beneficial activity: a direct vasodilatory effect, prevention of endothelial dysfunction, inhibition of platelet aggregation, and smooth muscle cell proliferation along with an anti-oxidant, anti-inflammatory, anti-obesity, anti-diabetic, and anti-atherosclerotic effects. This review provides an updated overview of the mechanisms by which flavonoids ameliorate cardiovascular risk factors, thus retarding cardiovascular disease progression.

\section{Key words}

Cardiovascular diseases; flavonoids; endothelial cells; hypertension; obesity.

\begin{abstract}
Abbreviations
BMI: body mass index; COX: cyclooxygenase; eNOS: endothelial NO synthase; HDL: high-density lipoprotein; ICAM-1: intercellular adhesion molecule I; IP3: inositol 1,4,5-tri-

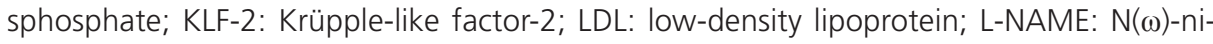
tro-L-arginine methyl ester; NrF2: nuclear factor erythroid-2 related factor 2; NF-kB: nuclear factor kappa-light-chain enhancer of activated B cell; PPAR- $\gamma$ : peroxisome proliferator-activated receptor gamma; ROS: reactive oxygen species; SHR: spontaneously hypertensive rat; SOD: superoxide dismutase; TGFBR1: transforming growth factor- $\beta$ (TGF- $\beta$ ) receptor 1; TNF- $\alpha$ : tumor necrosis factor- $\alpha$; TXA2: thromboxane A2; VCAM-1: vascular cell adhesion molecule 1; VLDL: very low-density lipoprotein; VSMC: vascular smooth muscle cell.
\end{abstract}

\section{INTRODUCTION}

Cardiovascular diseases, a group of disorders that affect blood vessels and heart, include coronary heart disease, myocardial infarction, and stroke. They represent the leading cause of death worldwide resulting in 17.9 million deaths every year (1). Several risk factors are associated with the incidence of cardiovascular diseases. These include non-modifiable (age, gender, ethnicity, and family history) and modifiable risk factors (hypertension, hyperglycemia, obesity, oxidative stress, physical inactivity, smoking, inappropriate diet, mental stress, and others) that are not independent but often occur simultaneously $(2,3)$. In this scenario, diet plays a critical role: excessive intake of saturated fat, processed red meat, sugar, sodium, along with low intake of fruits, vegetables, whole grain, fibers, and legumes are associated with a high risk of cardiovascular diseases (4). On the other 
hand, plant-based diets are seemed to prevent the occurrence of cardiovascular diseases (5), due to the high content of vegetable proteins, mono- and poly-unsaturated fat, fibers, and bioactive compounds, the latter endowed with several biological functions such as antioxidant and anti-inflammatory activities (6).

Flavonoids are a class of plant-derived bioactive compounds synthesized from the amino acid phenylalanine through the shikimic acid pathway (7). Flavonoids were first discovered in 1930 by Albert Szent-Gyorgyi, a Hungarian scientist, who termed them as vitamin P. However, interest in the pharmacological and nutraceutical features of these bioactive compounds was boosted only during the 90s, after the publication of the French paradox, an epidemiological study highlighting the low incidence of coronary heart disease in the French population despite its high daily intake of saturated fats. This paradox, ascribed to the consumption of red wine and polyphenols therein (8), stimulated researchers all over the world to investigate flavonoid beneficial effects at cellular, animal, and human levels. Nowadays, flavonoids are recognized as pleiotropic compounds exhibiting a wide array of biological and pharmacological effects such as antioxidant, antitumor, antidiabetic, antimicrobial, cardio-protective, and neuroprotective activities $(9,10)$. More importantly, several clinical trials and epidemiological studies have correlated flavonoid intake with a low incidence of cancer $(11,12)$, cardiovascular diseases $(13,14)$, diabetes (15), obesity (16), Alzheimer's disease (17), and Parkinson disease (18). This review briefly discusses structural features and occurrence of flavonoids, and provides an overview of the mechanisms underpinning the beneficial effects towards cardiovascular diseases.

\section{FLAVONOIDS: CHEMISTRY AND OCCURRENCE}

Flavonoids are characterized by a diphenylpropane skeleton consisting of 15 carbon atoms arranged into two 6-carbon rings (named as
A- and B-ring) linked via an oxygen-containing, heterocyclic benzopyran C-ring (19). Based on oxidation and saturation of the $\mathrm{C}$ ring, or position of the B-ring, flavonoids are classified into eight classes: flavone, flavonol, flavanone, flavanonol, isoflavone, flavan-3-ol, anthocyanidin, and chalcone (figure 1). Flavones have a double bond between $\mathrm{C}-2$ and $\mathrm{C}-3$ and a ketone group at position 4 of the $\mathrm{C}$-ring. Also, flavonols have a double bond between $\mathrm{C}-2$ and $\mathrm{C}-3$, a ketone at $\mathrm{C}-4$, and, in addition, an $\mathrm{OH}$ group at $\mathrm{C}-3$. Unlike flavones, isoflavones have the B-ring attached to C-3 instead of C-2. Flavanones, also called dihydroflavones, have a saturated bond between C-2 and C-3 and a ketone group. Flavononols, also called dihydroflavonols, have a saturated bond between C-2 and C-3 and an $\mathrm{OH}$ group at $\mathrm{C}-3$ along with the ketone group. Flavan-3-ols, also called catechins, have an $\mathrm{OH}$ group at $\mathrm{C}-3$ but lack both the ketone group and the double bond between C-2 and C-3. Chalcones present the $\mathrm{C}$-ring open at $\mathrm{C}-2$. The last class anthocyanidins lacks the ketone group but have two double bonds between $\mathrm{C}-1$ and C-2, and C-3 and C-4 (20).

Flavonoids can be further diversified according to the substitutions on A- and B-rings, namely methylation, acylation, prenylation and, most commonly, by hydroxylation and glycosylation, which markedly influence their solubility, stability, and reactivity $(21,22)$.

Flavonoids are widely distributed in all plant parts including roots, shoots, leaves, flowers, and fruits (23). Dietary flavonoids can be found in fruits, vegetables, tea, coffee, and wine (24), different classes being characteristic of different plants. Celery, parsley, red peppers, chamomile, spinach, and ginkgo biloba, for example, are rich of flavones (25). Flavonols are abundantly present in many vegetables, fruits, and beverages such as lettuce, onions, kale, tomatoes, berries, apples, grapes, tea, and red wine (26). Flavanones are found in grapes and Citrus fruits such as oranges and lemons where they are responsible for the bitter taste of the juice and peel (27). Isoflavones, also known as phytoestrogens, are abundant in soybeans 


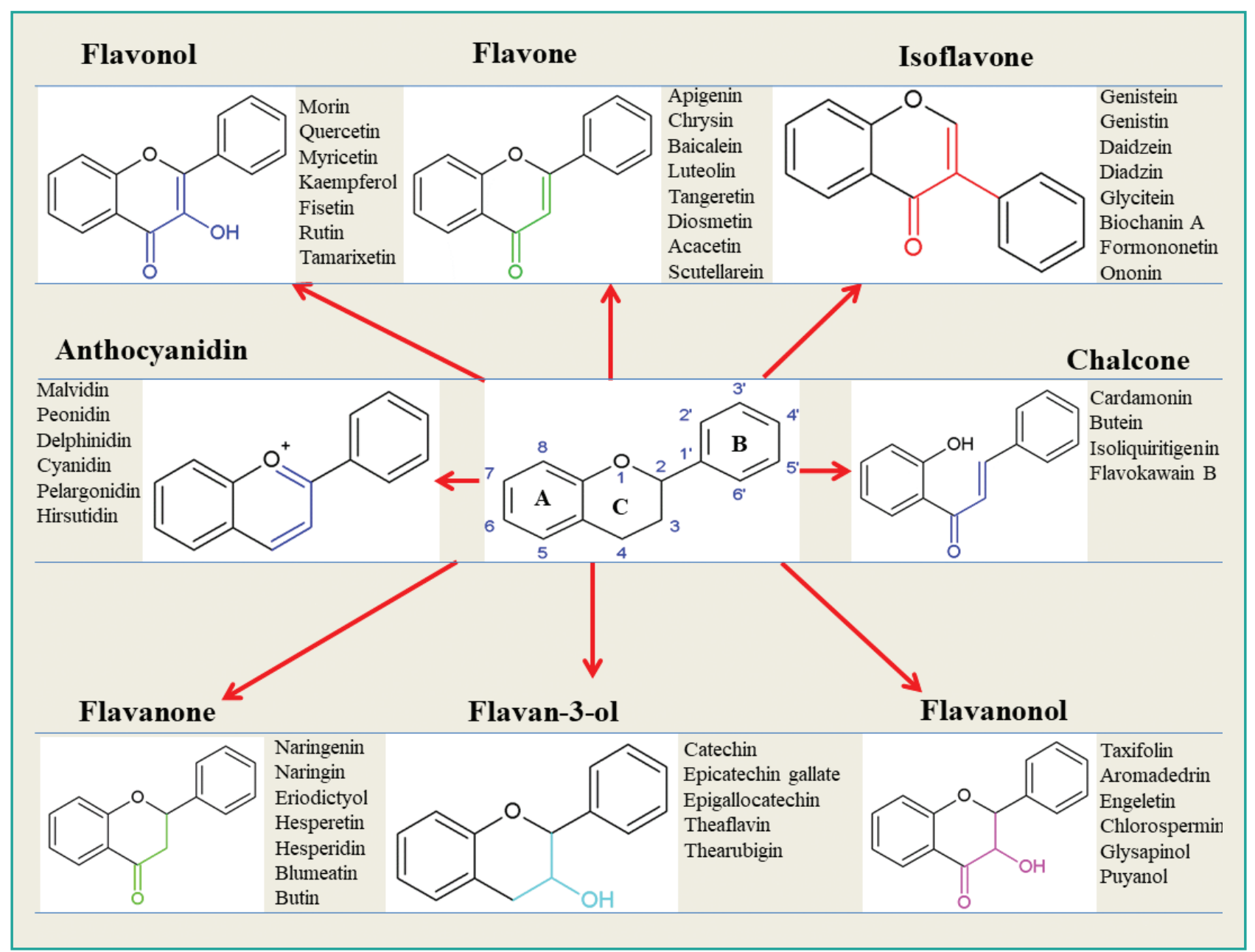

Figure 1. Structures and classification of the most common flavonoids.

and leguminous plants (28). Tea, bananas, apples, blueberries, peaches, and pears are rich of flavan-3-ols or catechins (29). Flavanonols are limited in their distribution to Citrus fruits and Glycosmis species (30). Finally, anthocyanidins are predominantly present in flowers and in the outer layers of fruits such as cranberries, black currants, grapes, and berries: they confer beautiful colors that depend on $\mathrm{pH}$ and chemical modifications of A- and B-rings (31).

\section{FLAVONOIDS AND CARDIOVASCULAR DISEASES}

Accumulating evidence obtained from in vitro, as well as in vivo clinical and epidemiological studies have highlighted the potential of flavonoids as beneficial agents capable of im- proving cardiovascular health and ameliorating risk factors associated with cardiovascular diseases (32). This effect has been generally ascribed to the direct antioxidant activity exhibited by this class of polyphenols. Flavonoids, however, may also improve vessel vasodilation via endothelium-dependent and/or -independent mechanisms, reduce the smooth muscle cell proliferation, inhibit platelet aggregation, ameliorate oxidative stress and inflammation, and exert an anti-obesity, anti-diabetic, and anti-hypertensive effect (33) (figure 2).

\section{FLAVONOIDS PROTECT AGAINST ENDOTHELIAL DYSFUNCTION}

Endothelial dysfunction is an independent predictor and a risk factor of cardiovascular diseas- 


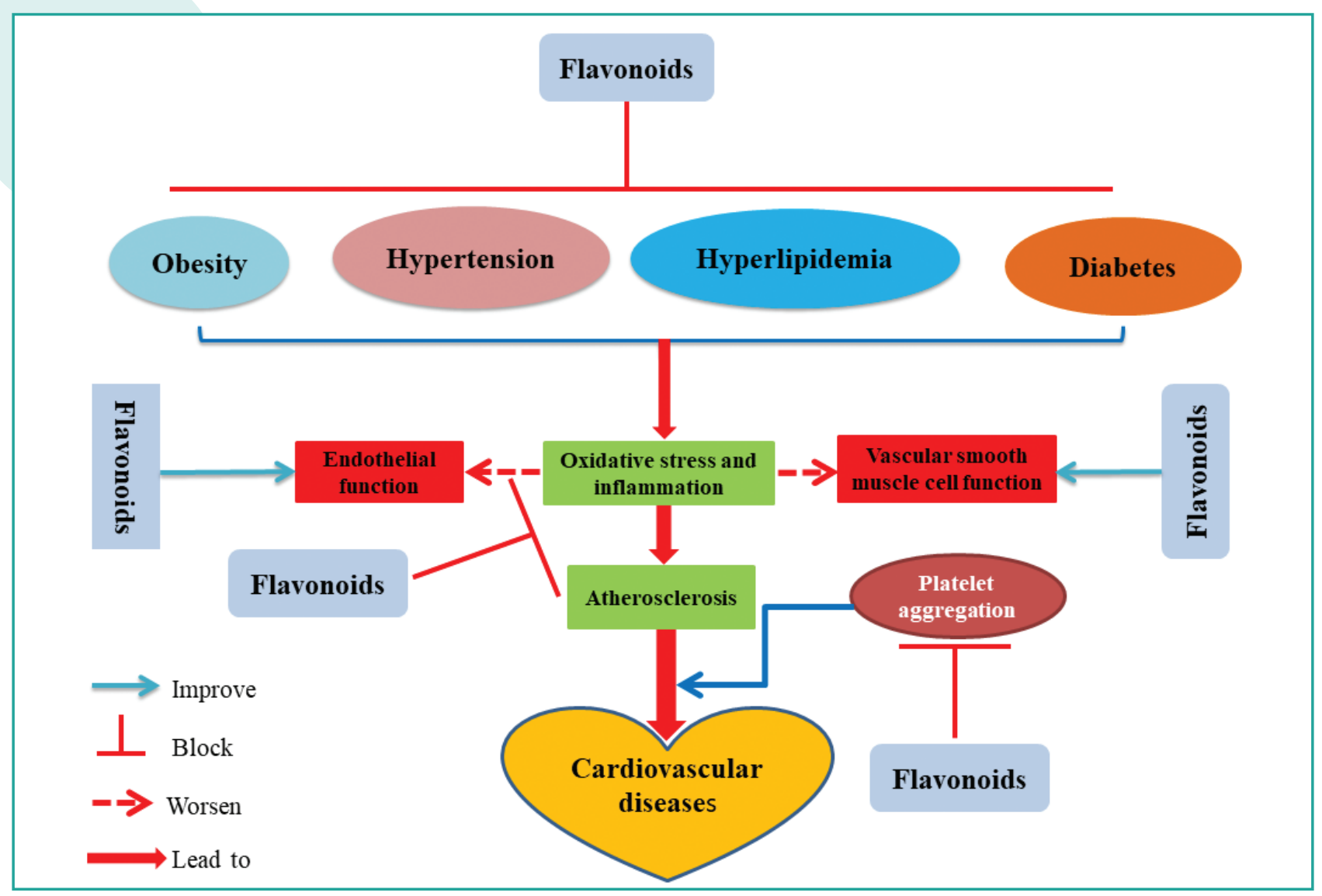

Figure 2. Summary of the mechanisms involved in the cardiovascular protective effect of flavonoids.

es. Its hallmarks are impaired endothelium-dependent vasodilation, due to reduced synthesis and/or increased degradation of $\mathrm{NO}$, and increased expression of chemokines and adhesion molecules, leading to a pro-inflammatory state of blood vessels (34). Dietary flavonoids improve endothelial dysfunction by stimulating NO synthesis through up-regulation of endothelial NO synthase (eNOS) expression, and/ or enhancing its activity $(35,36)$. For instance, luteolin and cynaroside from artichoke (Cynara scolymus L.) upregulate eNOS in human umbilical vein endothelial cells (EA.hy 926 and HUVECs) and potentiate the vasorelaxant response to acetylcholine in rat aortic rings (37). Similarly, the red wine polyphenol cyanidin and the tea catechins epicatechin gallate and epigallocatechin gallate stimulate eNOS expression in EA.hy926 endothelial cells (38).

Several flavonoids activate eNOS in a $\mathrm{Ca}^{2+}$-independent manner through the induction of
Ser-1179 phosphorylation and/or Thr-495 dephosphorylation [e.g., epigallocatechin gallate (39), quercetin (40), luteolin (41), hesperetin (42), hesperidin and naringin (43)] or through a $\mathrm{Ca}^{2+}$-dependent mechanism [e.g., quercetin (44) and (-)-epicatechin (45)]. Furthermore, flavonoids down-regulate caveloin-1 (a negative regulator of eNOS) expression or dissociate it from eNOS $(45,46)$, activate the chaperone protein HSP90 that is involved in eNOS activation (47), reduce the level of the eNOS inhibitor asymmetrical dimethylarginine $(48,49)$, or inhibit arginase to increase the level of the eNOS substrate arginine $(50,51)$, thus stimulating eNOS activity, and enhancing NO production. Moreover, quercetin, naringenin, and fisetin activate sirtuin-1 that, in turn, deacetylates eNOS, thus improving endothelial function (52). Also, flavonoids up-regulate eNOS transcription factor Krüpple-like factor-2 (KLF2) to increase NO production (53). 
Flavonoids protect NO from inactivation and prevent eNOS uncoupling by: 1) directly scavenging superoxide anion and preventing peroxynitrite formation (54); 2) inhibiting reactive oxygen species (ROS)-producing enzymes such as NADPH oxidase, 5-lipoxygenase, cyclooxygenases (COX), myeloperoxidase, and xanthine oxidase; 3) stimulating antioxidant enzymes such as superoxide dismutase (SOD), catalase, and glutathione peroxidase $(36,55)$; 4 ) increasing the activity of nuclear factor erythroid-2 related factor 2 (Nrf2) and up-regulating antioxidant enzymes such as NADPH:quinone oxidoreductase 1, hemeoxygenase-1, glutathione-S-transferase, and $\gamma$-glutamylcysteine ligase $(56,57)$. In this context, several in vitro studies demonstrated the endothelium-dependency of flavonoid-induced relaxation of different vascular preparations (58).

Furthermore, flavonoids protect against endothelial dysfunction by hampering the synthesis of prostaglandins (59), stimulating prostacyclin production (60), lowering the expression and release of endothelin-1 (53), limiting the cellular damage caused by either angiotensin II (61) or glucose (62), and down-regulating pro-inflammatory chemokines and adhesion molecules (63). Taken together, these studies suggest that flavonoids improve endothelial function by increasing $\mathrm{NO}$ production and inhibiting its degradation, by modulating prostaglandins, prostacyclin and chemokines synthesis, and by decreasing endothelial damage induced by pathological stimuli. However, numerous flavonoids identified to-date have not be assessed for this activity, hence future works should test the effect of yet unexplored flavonoids against endothelial dysfunction, characterize the structure-activity relationship, and validate the mechanism of action in an attempt to identify the scaffold responsible for this trait that, in turn, can be used as pharmacophore to synthesize more potent drugs. Additionally, the assessment models of endothelial dysfunction (cell lines, animal models or humans) should be strictly standardized to limit the discrepancies arising from the different stimuli employed and/or the level of endothelial dysfunction. Moreover, it is of great interest to clarify whether flavonoids protect endothelium from becoming dysfunctional, or reverse established endothelial dysfunction or both.

\section{FLAVONOIDS IMPROVE VASCULAR SMOOTH MUSCLE CELL FUNCTION}

Vascular smooth muscle cells (VSMCs), the structural and functional unit of blood vessels, provide the tonic contraction that allows blood flow (64). Flavonoids relax a plethora of conduit and resistance arteries and veins (58). Mechanistically, this vasodilation can be mediated by: 1) blockade of $\mathrm{Ca}^{2+}$ channels $(65,66)$; 2) opening of $\mathrm{K}^{+}$channels $(67,68)$; 3$)$ inhibition of $\mathrm{Ca}^{2+}$ release from (69) or stimulation of $\mathrm{Ca}^{2+}$ uptake to intracellular stores (70); 4) inhibition of protein kinase $C(71)$, Rho-kinase $(72,73)$, and phosphodiesterases $(74,75) ; 5)$ stimulation of soluble guanylyl cyclase (76), protein kinase A $(76,77)$, and protein kinase $G(78)$; and/or 6) stimulation of G-protein coupled receptors like $\beta$ adreno-receptor (79). Notably, the same flavonoid can induce vasodilation through one or more of these pathways. Altogether, flavonoids induce VSMC relaxation and/or inhibit their contraction. However, these studies are limited to the most common flavonoids and performed mainly on large conduit arteries. Therefore, future studies should focus on small resistance arteries that are responsible for blood pressure regulation. A molecular approach supported by computational analysis should complement the so far used classical pharmacological approach to precisely identify the molecular targets behind their vasodilatory effect. These two aspects are expected to identify the pharmacophore(s) responsible for the vasoactivity that can then be used to improve potency, efficacy and selectivity.

VSMCs are dynamic cells capable of changing their phenotype according to environmental cues. Under certain stimuli or pathological conditions such as hypertension, asthma, and atherosclerosis, VSMCs can transform from 
quiescent contractile into synthetic non-contractile phenotype capable of proliferation, migration, and vascular remodeling (80). Luteolin inhibits proliferation and migration of rat (A7r5) and human aortic vascular smooth muscle cells. This effect is mediated by inhibition of transforming growth factor- $\beta$ (TGF- $\beta$ ) receptor 1 (TGFBR1) signaling because: 1) phosphorylation of TGFBR1 and its downstream player Smad 2/3 was decreased and 2) overexpression of TGFBR1 relieved the inhibitory effect of luteolin on VSMC proliferation. Furthermore, Molecular simulation demonstrated the direct binding of luteolin to TGFBR1 (81). A similar effect has been reported for several flavonoids including quercetin (82), morin (83), cardamonin (84), xanthohumol (85), baicalin (86), kaempferol (87), apigenin (88), and genistein (89), etc. Various mechanisms underpin this activity including reduced activation of mitogen-activated protein kinase (82), modulation of p27KIP1, Akt, and MMP-9 functions (83), down-regulation of p38 MAPK, Akt, and extracellular regulated protein kinase phosphorylation (84), activation of maternally expressed gene 3/p53 signaling pathway (86), modulation of microRNA expression (87), and/or suppression of oxidative stress (90). In summary, flavonoids maintain non-synthetic, contractile phenotype of VSMC by inhibiting their proliferation, migration, and remodeling. However, the mechanisms underpinning this effect are not conclusive and deserve further investigation.

\section{FLAVONOIDS INHIBIT PLATELET AGGREGATION}

Platelet aggregation plays a pivotal role in the pathogenesis of acute and chronic cardiovascular diseases such as angina pectoris, stroke, and myocardial infarction (91). Platelet activation is a complex phenomenon involving multiple players, which fundamentally depends on cytosolic $\mathrm{Ca}^{2+}$ concentration. Several agents stimulate phospholipase $\mathrm{C}$ and $\mathrm{Ca}^{2+}$ release from intracellular stores via inositol 1,4,5-tris- phosphate (IP3): $\mathrm{Ca}^{2+}$ activates phospholipase A to release arachidonic acid that, in turn, is metabolized into thromboxane A2 (TXA2) by COX-1, thus triggering and amplifying platelet aggregation (92).

Flavonoids, either as flavonoid-rich beverage (tea, coffee, and wine) or as pure compounds, have shown an excellent anti-platelet aggregation activity in various experimental settings. Purple grape juice, for example, inhibits platelet aggregation both in vitro and in vivo; simultaneously increasing platelet derived $\mathrm{NO}$ production (93). Ingestion of $200 \mathrm{ml}$ of coffee reduces ex vivo platelet aggregation induced by collagen and arachidonic acid: this effect is caffeine-independent (94). The Citrus flavonoids naringin and naringenin show anti-aggregation activity, the former being more potent than the latter in peripheral blood platelets isolated from healthy human (95). Also, quercetin diminishes collagen-, thrombin- and ADP-dependent platelet aggregation in a concentration dependent manner: this effect is mediated by the inhibition of ATP release, P-selectin expression, intracellular $\mathrm{Ca}^{2+}$ mobilization, platelet integrin allb $\beta 3$ activation, as well as by an increase in the levels of cAMP and vasodilator-stimulated phosphoprotein (96). A similar effect has been reported for 3,6-dihydroxyflavone (97), apigenin (98), isorhamnetin, and tamarixetin (99), among others. Ravishankar and coworkers (2018) found that $\mathrm{OH}$ groups in the A-ring are key structural determinants for optimum platelet inhibitory activity, which decreases when $\mathrm{OH}$ is replaced with $\mathrm{CHO}$; conversely, $\mathrm{C}=\mathrm{O}$ substitution with $\mathrm{C}=\mathrm{S}$ or $\mathrm{B}$-ring modification seems less critical (100).

Flavonoid inhibition of platelet aggregation occurs preferentially through the blockade of signaling pathways initiated by activators such as ADP (97), collagen (101), TXA2 (102, 103), and thrombin (104) (figure 3). Furthermore, these natural products inhibit COX-1 (105) or phospholipase A and C activity (105, 106), reduce $\mathrm{Ca}^{2+}$ mobilization from the sarcoplasmic reticulum, increase cyclic nucleotide 


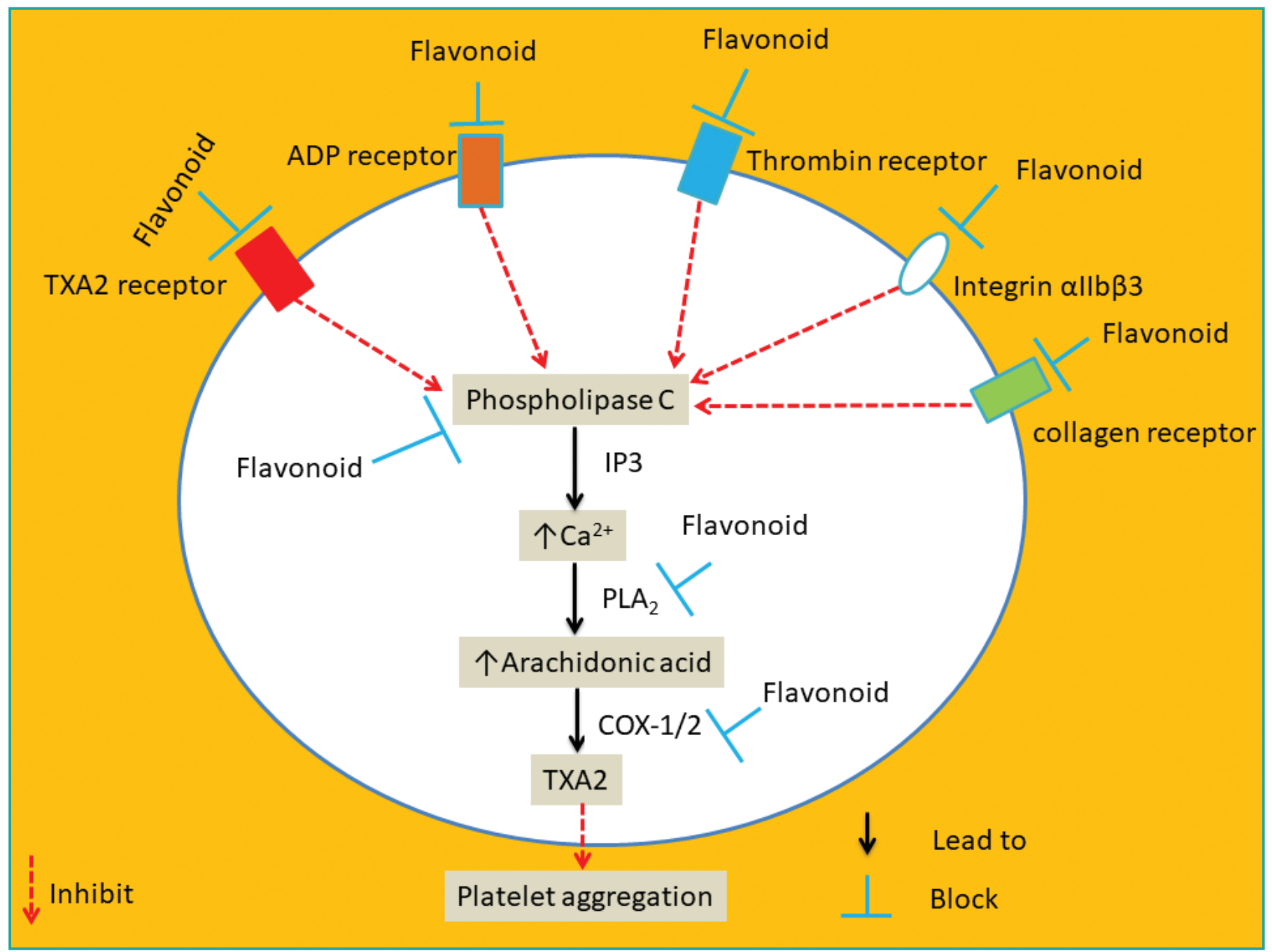

Figure 3. Mechanisms underpinning flavonoid-induced inhibition of platelet aggregation.

ADP: adenosine diphosphate; COX-1/2: cyclooxygenase-1/2; IP3: inositol 1,4,5-triphosphate; PLA2: phospholipase A2; PLC: phospholipase C; TXA2: thromboxane A2.

levels through phosphodiesterase inhibition, inhibit protein disulfide isomerase involved in the activation of platelet integrin $\alpha$ llb $\beta 3$ (107), stimulate NO production, ameliorate oxidative stress, and inhibit the expression of endothelial cell adhesion molecules such as vascular cell adhesion molecule 1 (VCAM-1), intercellular adhesion molecule 1 (ICAM-1), and E-selectin $(108,109)$. Taken together, these observations indicate that flavonoids counteract platelet aggregation exploiting several mechanisms including inhibition of the arachidonic acid pathway, and platelet degranulation. Future studies should analyze the anti-platelet aggregation activity of several flavonoids under standardized experimental conditions, to highlight the structural determinants, and validate the mechanism of action underpinning this activity. On the other hand, well controlled clinical trials involving large cohort of human subjects will be essential for a better understanding of the interaction between flavonoids and platelet function and to develop a clinical approach counteracting cardiovascular ailments.

\section{FLAVONOIDS AMELIORATE OXIDATIVE STRESS AND VASCULAR INFLAMMATION}

Oxidative stress is caused by an imbalance between production and scavenging of radicals or, more generally, oxidants. It plays a central 
role in the progression of cardiovascular diseases from various cardiovascular risk factors such as hypertension, obesity and vascular inflammation (110); therefore, it presents an important therapeutic target (111).

Flavonoids can prevent oxidative stress and alleviate vascular inflammation through a plethora of mechanisms (112). First, these polyphenols act as direct scavengers of oxidants such as superoxide anion, $\mathrm{H}_{2} \mathrm{O}_{2}$, hydroxyl radical, etc. The antioxidant activity of flavonoids is attributed to the presence of the double bond at position $\mathrm{C} 2-\mathrm{C} 3$, the $\mathrm{OH}$ group at position 3 on C-ring, the polyhydroxylated B-ring, and the $\mathrm{OH}$ group at position 5 on A-ring (113). However, they cannot be regarded as direct scavengers of free radicals in vivo as the reported antioxidant activity is usually detected at micromolar concentrations, which are hardly attainable in the blood stream due to their poor absorption, extensive metabolism, and rapid excretion. Hence, other mechanisms may account for oxidative stress amelioration, such as regulation of defense and repair systems along with the maintenance of a nucleophilic tone (i.e. protection against electrophiles, including radicals and oxidants (114)). Second, flavonoids decrease the expression and/or directly inhibit ROS-generating enzymes such as NADPH oxidase, xanthine oxidase, myeloperoxidase, lipoxygenase, COXs, and inducible NOS as well as limit ROS production at the mitochondrial electron transport chain $(115,116)$. Third, some flavonoids modulate antioxidant enzymes like catalase, SOD, and glutathione peroxidase, thus favoring ROS elimination (54, 117). Fourth, they activate the transcription factor Nrf2, which regulates the expression of about 250 genes coding for antioxidant proteins, detoxifying enzymes, and cytoprotective proteins $(57,118)$. Under normal conditions, $\mathrm{Nrf2}$ is located in the cytoplasm in association with its negative regulator Keap1, responsible for its ubiquitination and proteasomal degradation. Under oxidative stress conditions, Nrf2 disassociates from Keap1, translocates to the nucleus and binds to the promoter region of antioxidant response elements, thus initiating the transcription of antioxidant enzymes (119). Fifth, flavonoids inhibit nuclear factor kappalight-chain enhancer of activated B cells (NF$k B)$, thus alleviating the associated cardiovascular inflammation $(120,121)$. NF-kB is a family of inducible transcription factors that play a pivotal role in the expression of pro-inflammatory mediators and cell cycle regulators. It is normally sequestered in the cytoplasm by proteins known as IkB family, but once stimulated, enters the nucleus and binds to the NF-kB response site located on DNA to initiate the transcription of a plethora of genes coding for inflammatory cytokines, chemokines, adhesion molecules, anti-apoptotic factors, and cell cycle regulators, which contribute to inflammation, endothelial dysfunction, angiogenesis, VSMC proliferation and migration, and platelet adhesion $(122,123)$. Sixth, flavonoids chelate transition metal ions such as iron and copper that may contribute to the oxidative stress (114). Noticeably, flavonoids, like many antioxidants, show also pro-oxidant effects by: 1) direct production of hydroxyl radical via Fenton reaction, 2) oxidation of flavonoid phenoxyl radicals (the endproduct of ROS scavenging reaction by flavonoids), 3) inhibition of mitochondrial respiration, 4) oxidation of low molecular antioxidants, and 5) direct oxidation by peroxidases (113). Altogether, flavonoids protect the vascular system from oxidative stress due to their antioxidant activity and/or shifting the redox signaling balance towards a more antioxidant one. However, these mechanisms, drawn from studies conducted on cell lines, rodent animal models, and human studies, are actually inconclusive. Therefore, the link between flavonoid consumption, oxidative stress amelioration, and improvement of vascular diseases has still to be challenged. This problem may have arisen from the fact that oxidative stress cannot be reliably quantified in the biological system and the presence of complex food matrix containing flavonoids and extensive metabolism characterizing this class of natural compounds further complicate 
this issue. Hence, future studies should focus on improving the reliability of oxidative stress biomarkers, and standardizing the experimental conditions for flavonoid administration to rodents and humans.

\section{FLAVONOIDS AMELIORATE DYSLIPIDEMIA/HYPERLIPIDEMIA}

Dyslipidemia is defined as a persistent elevation of cholesterol, triglyceride, and low-density lipoprotein (LDL) levels along with prolonged decrease of high-density lipoprotein (HDL). Dyslipidemia is the major risk factor for atherosclerosis and coronary heart disease (124).

The lipid-lowering effect of flavonoids has been evaluated in different dyslipidemic animal models (125) and in humans (126). Quercetin, for example, markedly reduces serum cholesterol and triglycerides in rabbits fed high-fat diet for 12 weeks (127). Similarly, administration of this flavonoid with a high-cholesterol diet to rats results in a significant reduction of liver triglycerides (- 24\%), liver and serum cholesterol (- 22\% and - $20 \%$, respectively), and serum LDL (- 31\%) while doubling serum HDL cholesterol as compared to control animals (128).

Naringenin normalizes the levels of cholesterol, triglycerides, free fatty acids, very low-density lipoprotein (VLDL), and LDL, increases plasma $H D L$, lipoprotein lipase, and lecithin cholesterol acyltransferase, and reduces the expression of $\beta$-hydroxy $\beta$-methylglutaryl-CoA reductase in rats fed $20 \%$ ethanol for two months (129). Chrysin, orally administered to triton WR1339-induced hyperlipidemic female C57BL/6 mice, significantly decreases total cholesterol, LDL cholesterol, and triglyceride levels (130). Apigenin supplementation to $\mathrm{C} 57 \mathrm{BL} / 6 \mathrm{~J}$ mice fed high-fat diet for 16 weeks significantly decreases plasma levels of free fatty acids, total cholesterol, and apolipoprotein B (131).

The black tea flavonoids theaflavin and thearubigins markedly reduce cholesterol, $L D L$, and triglyceride levels while increasing
HDL level in rat fed high-cholesterol diet, theaflavin-based drink being more effective than thearubigins alone or theaflavin and thearubigins combination (132). The lemon fruit flavonoid eriocitrin does not affect hepatic total cholesterol or triglycerides though significantly decreasing total serum cholesterol, VLDL, LDL, triglyceride, and phospholipid levels in rat fed high-fat diet (133). A similar effect has also been demonstrated for epigallocatechin gallate (134), and rutin (135) in different dyslipidemic rat models.

Studies concerning the anti-dyslipidemic effect of flavonoids in humans are scarce. For example, quercetin supplementation gives rise to contrasting results either decreasing triglycerides and LDL or being ineffective (136, 137). A meta-analysis of five randomized control trials performed on this flavonoid evidenced only a reduction of total triglycerides at doses $>50 \mathrm{mg} /$ day (138).

The mechanisms underlying the lipid-lowering effect of flavonoids are numerous and include: 1) decreased absorption of cholesterol and lipids; 2) up-regulation of genes involved in fatty acid oxidation, Kreb's cycle, oxidative phosphorylation, and electron transport chain; 3) down-regulation of lipolytic and lipogenic genes; 4) inhibition of enzymes involved in triglyceride and cholesterol biosynthesis; 5) enhanced cholesterol excretion in bile acid and inhibition of its extrahepatic circulation; and 6) enhanced lipid clearance by increasing LDL receptor expression on hepatocytes or by reducing its recycling $(131,139)$. These studies suggest that flavonoids exert an excellent lipid-lowering effect in different dyslipidemic animal models by reducing the levels of total cholesterol, LDL, free fatty acids, and triglycerides as well as by increasing HDL level. Future studies are needed to test more flavonoids on dyslipidemic and healthy control animals, to further characterize the mechanism of action. Furthermore, clinical trials involving large number of human subjects are needed to establish the link between flavonoid consumption and improvement of lipid profile. 


\section{FLAVONOIDS IMPROVE HYPERTENSION}

Hypertension represents the main risk factor for several cardiovascular diseases including coronary heart disease, stroke, and cardiac arrhythmia (140). The anti-hypertensive effect of flavonoids has been claimed based on data obtained in in vitro blood vessel assays, animal models, and subsequently confirmed by human intervention and population studies (141). In vitro studies performed on blood vessels obtained from different animal species highlighted an excellent vasodilating activity of quercetin, naringenin, galangin, chrysin, apigenin, fisetin, tamarixetin, eupatorin, morin, kaempferol, genistein, and other flavonoids (58). In animal models, quercetin lowers high blood pressure of spontaneously and salt-induced hypertensive rats $(142,143)$. Interestingly, the glucuronidated form of this flavonoid also decreases blood pressure of spontaneously hypertensive rat (SHR) after deconjugation at the target tissue by $\beta$-glucuronidase (144). Similarly, chrysin shows an excellent anti-hypertensive effect in SHR and $N(\omega)$-nitro-L-arginine methyl ester (L-NAME)-induced hypertensive rats $(145,146)$. This effect has also been reported for catechin (147), epigallocatechin gallate (148), hesperidin (149), and other flavonoids (150) in various animal models of hypertension. Noticeably, these studies demonstrate that flavonoids do not modify blood pressure in normotensive rats.

Human data are limited and sometimes conflicting. Quercetin, for example, does not affect blood pressure in healthy men and women (151) or in rheumatoid arthritis patients (152), but reduces it in women with type-2 diabetes (153), in hypertensive patients (154), in obese individuals with metabolic syndrome traits (155), in healthy male smokers (136), and in healthy male carrying apolipoprotein $\mathrm{E}$ genotype (137). A meta-analysis of these seven clinical studies (enrolling 587 patients) shows that quercetin significantly reduces both systolic and diastolic blood pressure, though only at doses > $500 \mathrm{mg} /$ day (156). Recently,
quercetin-3-O-glucoside does not affect blood pressure in healthy volunteers (157).

In a cross-over clinical trial, supplementation with a high-flavonoid sweetie juice (rich in naringin and narirutin) followed by a low-flavonoid sweetie juice (25\% of naringin and $30 \%$ of narirutin as compared the former), each for 5 weeks, significantly decreased both diastolic and systolic blood pressure in twelve stage-1 hypertensive patients. The high-flavonoid juice was particularly effective in reducing diastolic blood pressure (158). Furthermore, the prolonged consumption or even a single intake of a hesperidin-enriched orange juice reduced systolic blood pressure in a randomized clinical trial involving pre- and stage-1 hypertensive individuals (159). Altogether, flavonoids exhibit an anti-hypertensive effect when administered to hypertensive models though only at high concentrations and without affecting the normotensive ones. This effect seems to be mediated by their excellent endothelium-dependent and -independent vasorelaxant activity as well as by alleviation of oxidative stress (160). In the future, clinical trials involving large number of human subjects with established hypertension and healthy controls should be conducted to examine the anti-hypertensive effect of flavonoids other than quercetin. Additionally, since flavonoids do not modify blood pressure in normotensive subjects, it would be interesting to assess if flavonoids protect against development of hypertension, thus supporting the epidemiological studies already associating flavonoid consumption to a low incidence of the disease $(161,162)$.

\section{FLAVONOIDS ALLEVIATE OBESITY}

Obesity, an accumulation of excessive fat giving rise to body mass index $(\mathrm{BMI}) \geq 30$, affects human health and reduces the quality of life. Its occurrence increases the incidence of hypertension and type-2 diabetes, and is an independent risk factor for cardiovascular diseases such as coronary heart disease, and myocardial infarction (163). Several cellular, 
animal models and human intervention studies demonstrate the anti-obesity activity of flavonoids $(164,165)$. At cellular level, the Citrus flavonoid hesperetin reduces lipid accumulation in 3T3-L1 cells by $63 \%$ at $25 \mu \mathrm{M}$ and decreases ROS generation compared to control (166). Similarly, kaempferol inhibits adipogenesis in pre- and mature adipocytes. In 3T3-L1 cells, this effect is mediated by down-regulation of CCAAT enhancer binding protein alpha (Cebpa) mRNA (encoding for a transcription factor involved in the modulation of proteins that regulate cell cycle and body weight homeostasis) and up-regulation of Pnpla2 and Lipe genes expression (both genes encode for enzymes involved in triglyceride hydrolysis) (167). A similar activity has been described also for quercetin (168), chrysin (169), and apigenin (170), among others.

The flavonol myricetin administered to obese C57BL/6 mice fed high-fat diet significantly reduces body weight and ameliorates several obesity-associated parameters such as serum glucose, triglyceride, and cholesterol levels. It improves also oxidative stress markers such as glutathione peroxidase activity, total antioxidant capacity, malondialdehyde level, as well as inflammatory markers [e.g., tumor necrosis factor- $\alpha$ (TNF- $\alpha$ )] (171). Galangin reduces body weight, energy intake, liver weight, and parametrial adipose tissue in obese female albino rats fed cafeteria diet for 6 weeks. It also restores the level of serum lipids, counteracts lipid peroxidation and limits accumulation of hepatic triglycerides (172). Chrysin significantly reduces body weight, $\mathrm{BMI}$, abdominal circumference-thoracic circumference ratio, calorie intake while increasing locomotor activity and fecal cholesterol excretion in obese rats fed high-fructose diet compared to control (173). More interestingly, apigenin administered to high fat-diet induced obese mice, reduces both body weight and visceral adipose tissues, by binding to non-phosphorylated STAT3 in visceral adipose tissues, thus reducing its transcriptional activity. This, in turn, decreases the expression of cluster of differentiation 36
(CD36) that, under physiological conditions, controls the level of peroxisome proliferator-activated receptor gamma (PPAR- $\gamma$ ), a critical nuclear factor for adipogenesis (174).

So far, clinical trials assessing flavonoids in humans have produced conflicting results (175). Akhlaghi and coworkers (2018) meta-analyzed 58 studies published until 2018 concluding that flavanols have the potential for reducing $\mathrm{BMI}$ and waist circumference in the overall population. Stratification analysis shows that flavanols decrease BMI also in the Asian and in subjects under 50 year-olds, or in those consuming doses $>500 \mathrm{mg} /$ day. Similarly, isoflavones reduce the BMI in non-Asian populations or in those consuming doses $\geq 75 \mathrm{mg} /$ day. However, neither the BMI nor the waist circumference is modified by flavonols, flavanones, and anthocyanins (163).

Several mechanisms underlying the anti-obesity effect of flavonoids were hypothesized:

1. reduction of appetite and food intake via modulation of neuropeptide and leptin, which control the hunger/satiety center (176);

2. reduction in carbohydrate and lipid digestion and/or absorption through the decreased activity of digestive enzymes such as pancreatic lipase (177), $\alpha$-amylase (178), and $\alpha$-glucosidase (179);

3. modulation of lipid metabolism in favor of suppressed adipocyte differentiation and/or adipogenesis and enhanced lipolysis, $\beta$-oxidation, and apoptosis, through a complex hormonal and biochemical signaling involving CCAAT-enhancer binding protein (C/ $\mathrm{EBP} \alpha, \beta, \delta)$, and PPAR- $\gamma(162)$;

4. induction of adipose tissue browning through the modulation of, for example, AMPK and/or sirtuin-1 signaling pathways that, in turn, induce mitochondrial biogenesis and uncoupling protein-1 expression and, hence, energy expenditure, as demonstrated for rutin (180), pentamethylquercetin (181), quercetin (182), and other flavonoids (183);

5. normalization of obesity-associated gut dysbiosis, as reported for quercetin, rutin, 
catechin, procyanidin, epigallocatechin gallate, and other flavonoids $(184,185)$.

In summary, flavonoids exhibit a powerful anti-adipogenic activity at cellular and organism level, particularly under obesity conditions. This effect involves a wide array of mechanisms: inhibition of lipid digestion and absorption, modulation of metabolism, and induction of adipose tissue browning. Controlled clinical trials are recommended to assess the anti-obesity effect of single flavonoids in large cohorts of patients.

\section{FLAVONOIDS IMPROVE HYPERGLYCEMIA AND DIABETES}

Type-2 diabetes is not only a metabolic disorder characterized by persistent hyperglycemia but also an independent risk factor for cardiovascular diseases, the latter representing the most frequent cause of morbidity and mortality in diabetic patients (186). Flavonoids seem to exert antidiabetic effects as demonstrated in several animal models and clinical trials (187). In particular, diosmin administered orally for 4 weeks to streptozotocin-induced diabetic rats significantly restores blood sugar level, improves lipid profile, reduces malondialdehyde level, and increases glutathione level and SOD activity (188). Similarly, apigenin improves diabetes-associated nephropathy in streptozotocin-induced diabetic rats as compared to control animals and prevents renal dysfunction, oxidative stress, inflammation, collagen deposition, glomerulosclerosis, and fibrosis (189). A promising anti-diabetic effect characterizes also other flavonoids like quercetin (190), morin (191), hesperetin (192), and kaempferol (193) as demonstrated in various diabetic animal models.

Unlike studies on animal models, human clinical trials are limited to few flavonoid-rich food or flavonoid mixtures: these studies show sometimes inconsistent results. For instance, flavonoids intake was not associated with a lower risk of type-2 diabetes in post-meno- pausal women (194), whereas in a large cohort study involving 340,234 participants from 8 European countries, flavanols (monomer, dimer or proanthocyanidin with low degree of polymerization) and flavonols (in particular myricetin) were associated with a lower risk of type-2 diabetes (195). A similar result was observed with quercetin in the Chinese population (196). However, the consumption of flavonols, flavones, quercetin, apigenin, myricetin, kaempferol, and luteolin was not associated with type-2 diabetes incidence (197).

In a cross-sectional study performed on 1997 women aged 18-76 years, a high intake of anthocyanins and flavones was associated with low peripheral insulin resistance and inflammation biomarkers; the other flavonoid subclasses assessed were ineffective (198). Similarly, a follow-up study of 200,000 US women and men demonstrated that high anthocyanin consumption lower the risk of type2 diabetes; this beneficial effect seems to be specifically correlated to this class of flavonoids as no association was detected with the total flavonoid intake (199). However, a subsequent meta-analysis considering four studies involving 284,806 participants found that total intake of flavonoids is indeed associated with a lower risk of type-2 diabetes (200). The same conclusion was reached by an independent meta-analysis of nine prospective cohort studies, involving 172,058 participants, for flavonols, flavan-3-ols, and isoflavones (201).

Xu et al. (2018) demonstrated in a meta-analysis of eight prospective studies involving 312,015 participants that, beyond total flavonoids, anthocyanidins, flavan-3-ols, flavonols, and isoflavones are inversely correlated with type-2 diabetes risk (15). In a meta-analysis of 18 studies, involving 457,922 participants, a high intake of coffee, decaffeinated coffee, or tea was associated with a low risk of type2 diabetes (202), in line with two studies that took into account tea consumption $(203,204)$. In a previous study, however, tea consumption shows only a borderline effect (197). 
Various mechanisms underpin the anti-diabetic effect of these natural compounds (as depicted in figure 4): 1) modulation of digestive enzymes and, hence, lipid and carbohydrate absorption; 2) increased expression and translocation of glucose transporter-4; 3) modulation of hepatic enzymes involved in glucose metabolism, enhancing glucose uptake and storage; 4) protection of $\beta$-cells from apoptosis and enhancement of insulin secretion; 5 ) increased expression and activation of PPAR- $\gamma$, thus improving glucose uptake and insulin sensitivity; 6) activation of the AMP-kinase pathways; 7) inhibition of tyrosine kinase activity; and 8) down-regulation of the NF-kB pathway (205-207). Altogether, flavonoids seem to have a promising anti-diabetic effect in particular in animal models of diabetes. In humans, this ef- fect appears to be conferred by flavonoid-rich foods rather than by individual flavonoids. Future studies should address the anti-diabetic effect of individual flavonoids in clinical trials and elucidate the mechanism of action, in an attempt to develop these pleiotropic compounds as anti-diabetic drugs.

\section{FLAVONOIDS ATTENUATE ATHEROSCLEROSIS DEVELOPMENT}

Atherosclerosis is the major direct cause of cardiovascular diseases such as myocardial infarction, stroke, and heart failure. It initiates with fat deposition on vessel wall, which develops forming plaques that, in turn, either restrict blood flow or induce thrombosis (208). Several flavonoids hamper atherosclerosis pathogene-

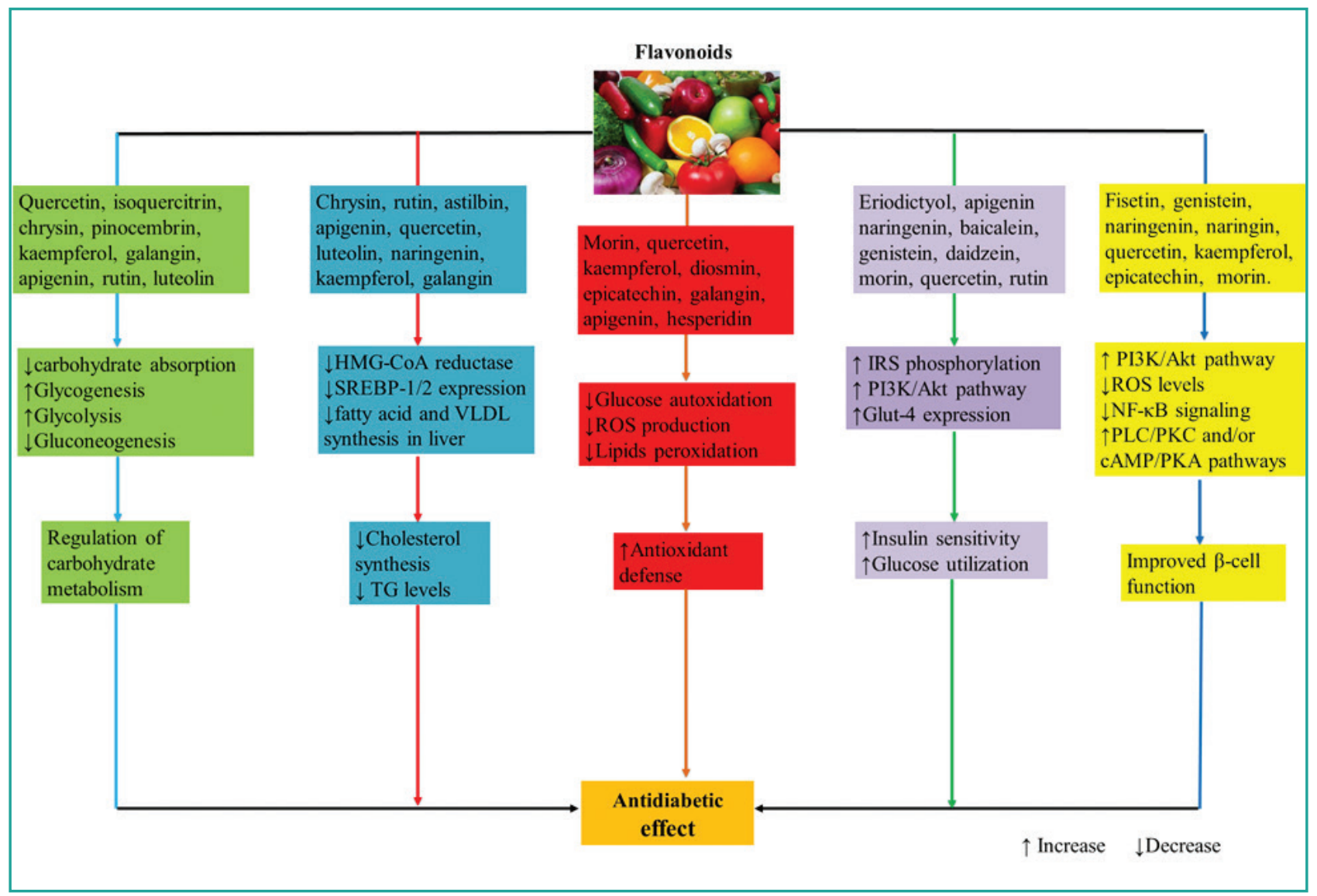

Figure 4. Mechanisms involved in flavonoid anti-diabetic effects.

CAMP: cyclic adenosine monophosphate; Glut-4: glucose transporter 4; HMG-CoA: 3-hydroxy-3-methylglutaryl-coenzyme A; IRS: insulin receptor substrate; PI3K: phosphatidylinositol-3-kinase; PKA: protein kinase A; PKC: protein kinase C; PLC: phospholipase C; ROS: reactive oxygen species; SREBP-1c: sterol regulatory element-binding protein; TG: triglycerides; VLDL: very low-density lipoprotein. 
sis in various animal models (209). In particular, in apolipoprotein E knockout mice fed highfat diet, quercetin ameliorates atherosclerosis-associated alterations by enhancing autophagy, up-regulating p21 and p53 expression, and down-regulating that of TNF- $\alpha, \mathrm{IL}-1 \beta$, IL-18, and mTOR (210). Interestingly, apigenin shows an anti-atherosclerotic effect both in RAW264.7 macrophages and apolipoprotein $E$ knockout mice due to the upregulation of ATP Binding Cassette Subfamily A 1 (ABCA1) expression via miR-33 repression that, in turn, increases cholesterol efflux and decreases foam cells formation, and the down-regulation of inflammation-associated markers like TLR4, MyD88, $p-\mid \kappa B-\alpha$, and nuclear NF-kB p65 subunit (211). Also fisetin shows a promising anti-atherosclerotic effect in apolipoprotein $\mathrm{E}$ knockout mice fed high-fat diet: in fact, it reduces atherosclerotic plaque formation and lipid accumulation in the aortic sinus. This effect is mediated by down-regulation of PCSK9, LOX-1, p53, p21, and p16 expression (212). Kaempferol improves the inflammatory status in atherosclerotic rabbits fed high cholesterol-diet. This effect is mediated by down-regulation of inflammatory markers such as TNF- $\alpha$, IL-1 $\beta$, malondialdehyde, E-selectin, ICAM-1, VCAM-1, and monocyte chemoattractant protein-1 as well as enhancement of serum SOD activity (213).

Studies examining the effect of flavonoids on human atherosclerosis are limited and usually confined to flavonoid-rich food rather than single molecules. For instance, tea but not coffee, caffeine or caffeinated coffee consumption is inversely associated to coronary artery plaque progression (214). In Danish population, a daily intake of flavonoids reduces by $14 \%$ the risk of atherosclerosis, particularly in smokers and alcohol consumers (215).

The main mechanism responsible for the anti-atherosclerotic effect of flavonoids is inhibition of LDL oxidation and, hence, foam cell formation, which is considered the hallmark of atherosclerosis progression. This is achieved by, for example, quercetin enhancement of cholesterol efflux from foam THP-1 cells treated with oxidized LDL, an effect mediated by the up-regulation of PPAR- $\gamma$ and ABCA1 expression (216). Quercetin enhances also the viability of RAW264.7 macrophages treated with oxidized LDL, and decreases intracellular accumulation of cholesterol and lipids. Up-regulation of $A B C A I, A B C G 1$, and liver $X$ receptor- $\alpha$ $(L X R-\alpha)$ along with down-regulation of PCSK9, p53, p21, and p16 seems involved in this activity (217). Similarly, chrysin inhibits foam cell formation by both increasing efflux and decreasing influx of cholesterol. This effect is mediated by up-regulation of PPAR- $\gamma, \mathrm{LXR}-\alpha$, $A B C A 1$, and $A B C G 1$, as well as down-regulation of scavenger receptor A1 (SR-A1) and SRA2 (218). A similar effect has been reported also for baicalin (219), kaempferol (220), and fisetin (221).

Other mechanisms participate in the anti-atherosclerotic effect of flavonoids: regulation of lipid metabolism in favor of enhanced cholesterol excretion (222); inhibition of endothelial cell senescence induced by oxidized LDL (223); enhanced autophagic activity of foam cells (224); and reduced plaque rupture by metalloproteinase inhibition (225). In conclusion, flavonoids exhibit, at least in animal models, a promising anti-atherosclerotic effect, which is mediated by reduced lipid oxidation, lipid accumulation, and foam cell formation. Clinical and epidemiological studies are now necessary to discern whether flavonoid consumption is associated with low risk of atherosclerosis development in human population.

\section{CONCLUSIONS AND LIMITATIONS}

Flavonoids are endowed with a plethora of biological and pharmacological activities, which seem responsible for the low incidence of cardiovascular diseases. The cardioprotective function of flavonoids is mediated through a paradigm of mechanisms that collectively ameliorate cardiovascular risk factors and retard the development of diseases. Evidence supporting their claimed cardioprotective ef- 
fect is based on studies carried out mainly on cellular and animal models, that are supported by a few human clinical intervention and epidemiological studies. There is still a need to carry out large clinical cohort studies, involving humans from different ethnics, using single pure or standardized mixtures of flavonoids, to precisely identify the link between flavonoid consumption and beneficial cardiovascular activity. However, flavonoid-based drugs development still suffers many limitations and challenges, including purification high cost and low yield, low solubility and stability, extensive metabolism in small intestine and liver, low bioavailability, interaction with intestinal microflora, and high promiscuity of interaction with concomitant therapies. More importantly, human clinical trials, either prospective observational or prospective interventional, still represent a hurdle due to the small and slow effects produced by flavonoids

\section{REFERENCES}

1. Jagannathan $R$, Patel $S$, Ali M, Narayan KMV. Global updates on cardiovascular disease mortality trends and attribution of traditional risk factors. Curr Diab Rep 2019;19(7):44.

2. Tangvarasittichai S. Oxidative stress, insulin resistance, dyslipidemia and type 2 diabetes mellitus. World J Diabetes 2015;6(3):456-480.

3. Petrie JR, Guzik TJ, Touyz RM. Diabetes, hypertension, and cardiovascular disease: clinical insights and vascular mechanisms. Can J Cardiol 2018;34(5):575-584.

4. Casas R, Castro-Barquero S, Estruch R, Sacanella E. Nutrition and cardiovascular health. Int J Mol Sci 2018;19(12):3988.

5. Satija A, Hu FB. Plant-based diets and cardiovascular health. Trends Cardiovasc Med 2018;28(7):437-441.

6. Sharifi-Rad M, Anil Kumar NV, Zucca P, et al. Lifestyle, oxidative stress, and antioxidants: back and forth in the pathophysi- in vivo. Furthermore, appropriate, standardized, and reliable biomarkers to trace these effects are required to reach a universally recognized conclusion on this still open issue: "flavonoids: friends or foes?".

Although the physiological effects on biomarkers for cardiovascular disease are much lower than those expected by drugs used for the same purpose, flavonoids can easily be incorporated into the daily diet and usually present no adverse effects.

\section{ACKNOWLEDGEMENTS}

The author would like to thank Dr. Fabio Fusi for his assistance in revising this paper.

\section{CONFLICT OF INTERESTS}

The authors declare that they have no conflict of interests.

ology of chronic diseases. Front Physiol 2020;11:694

7. Falcone F, Maria L, Rius S, Casati P. Flavonoids: biosynthesis, biological functions, and biotechnological applications. Front Plant Sci 2012;3:222

8. Sun AY, Simonyi A, Sun GY. The "French Paradox" and beyond: neuroprotective effects of polyphenols. Free Radic Biol Med 2002;32:314-318.

9. Busch C, Burkard M, Leischner C, Lauer UM, Frank J, Venturelli S. Epigenetic activities of flavonoids in the prevention and treatment of cancer. Clin Epigenetics 2015;7:64.

10. Jucá MM, Cysne Filho FMS, de Almeida $\mathrm{JC}$, et al. Flavonoids: biological activities and therapeutic potential. Nat Prod Res 2020;34:692-705.

11. Chang $H$, Lei L, Zhou $Y$, Ye F, Zhao G. Dietary flavonoids and the risk of colorectal cancer: an updated meta-Analy- 
sis of epidemiological studies. Nutrients 2018; 10:950.

12. Bondonno NP, Dalgaard F, Kyrø C, et al. Flavonoid intake is associated with lower mortality in the danish diet cancer and health cohort. Nat Commun 2019;10:3651.

13. Kim Y, Je Y. Flavonoid intake and mortality from cardiovascular disease and all causes: A meta-analysis of prospective cohort studies. Clin Nutr ESPEN 2017;20:68-77.

14. Parmenter $B H$, Croft KD, Hodgson JM, et al. An overview and update on the epidemiology of flavonoid intake and cardiovascular disease risk. Food Funct 2020;11:6777-6806.

15. Xu H, Luo J, Huang J, Wen Q. Flavonoids intake and risk of type 2 diabetes mellitus: A meta-analysis of prospective cohort studies. Medicine 2018;97:e0686.

16. Vernarelli JA, Lambert JD. Flavonoid intake is inversely associated with obesity and c-reactive protein, a marker for inflammation, in US adults. Nutr Diet 2017;7(5): e276.

17. Shishtar E, Rogers GT, Blumberg JB, Au $\mathrm{R}$, Jacques PF. Long-term dietary flavonoid intake and risk of Alzheimer disease and related dementias in the Framingham Offspring Cohort. Am J Clin Nutr 2020;112(2):343-353.

18. Gao X, Cassidy A, Schwarzschild MA, Rimm $E B$, Ascherio A. Habitual intake of dietary flavonoids and risk of Parkinson disease. Neurology 2012;78(15):1138-1145.

19. Panche AN, Diwan AD, Chandra SR. Flavonoids: an overview. J Nutr Sci 2016;5,e47.

20. Rauter AP, Ennis M, Hellwich $K H$, et al. Nomenclature of flavonoids (IUPAC Recommendations 2017). Pure Appl Chem 2018; 90,1429.

21. Kumar S, Pandey AK. Chemistry and biological activities of flavonoids: an overview. Sci World J 2013;162750.

22. Yang $X$, Jiang $Y$, Yang J, et al. Prenylated flavonoids, promising nutraceuticals with impressive biological activities. Trends Food Sci Technol 2015;44:93-104.
23. Mouradov A, Spangenberg G. Flavonoids: a metabolic network mediating plants adaptation to their real estate. Front Plant Sci 2014;5:620.

24. D'Archivio M, Filesi C, Di Benedetto R, Gargiulo R, Giovannini C, Masella R. Polyphenols, dietary sources and bioavailability. Ann Ist Super Sanita 2007;43:348-361.

25. Hostetler GL, Ralston RA, Schwartz SJ. Flavones: food sources, bioavailability, metabolism, and bioactivity. Adv Nutr 2017:8:423-435.

26. Zhang Y, Li Y, Cao C, et al. Dietary flavonol and flavone intakes and their major food sources in chinese adults. Nutr Cancer 2010;62:1120-1127.

27. Barreca D, Gattuso G, Bellocco E, et al. Flavanones: citrus phytochemical with health-promoting properties. Biofactors 2017; 43:495-506.

28. Křrižová L, Dadáková K, Kašparovská J, Kašparovský T. Isoflavones. Molecules 2019;24:1076.

29. Auger C, Al-Awwadi N, Bornet A, et al. Catechin and procyanidins in mediterranean diet. Food Res Int 2004;37:233-245.

30. Lukaseder B, Vajrodaya S, Hehenberger $\mathrm{T}$, et al. Prenylated flavanones and flavanonols as chemical markers in Glycosmis species (Rutaceae). Phytochemistry 2009;70:1030-1037.

31. Krga I, Milenkovic D. Anthocyanins: from sources and bioavailability to cardiovascular-health benefits and molecular mechanisms of action. J Agr Food Chem 2019;67:1771-1783.

32. Sánchez $M$, Romero $M$, Gómez-Guzmán M, Tamargo J, Pérez-Vizcaino F, Duarte J. Cardiovascular effects of flavonoids. Curr Med Chem 2019;26:6991-7034.

33. Myron G. Flavonoids and cardiovascular disease. Pharm Biol 2004;42:21-35.

34. Versari D, Daghini E, Virdis A, Ghiadoni L, Taddei S. Endothelial dysfunction as a target for prevention of cardiovascular disease. Diabetes Care 2009;32(2):314-321 
35. Grassi D, Desideri G, Di Giosia P, et al. Tea, flavonoids, and cardiovascular health: endothelial protection. Am J Clin Nutr 2013;98:30.

36. Duarte J, Francisco V, Perez-Vizcaino F. Modulation of nitric oxide by flavonoids. Food Funct 2014;5:1653-1668.

37. Li H, Xia N, Brausch I, Yao Y, Förstermann U. Flavonoids from artichoke (Cynara scolymus L.) up-regulate endothelial-type nitric-oxide synthase gene expression in human endothelial cells. J Pharmacol Exp Ther 2004;310:926-932.

38. Wallerath T, Li H, Gödtel-Ambrust U, Schwarz PM, Förstermann U. A blend of polyphenolic compounds explains the stimulatory effect of red wine on human endothelial NO synthase. Nitric Oxide 2005;12:97-104.

39. Lorenz M, Wessler S, Follmann E, et al. A constituent of green tea, epigallocatechin-3-gallate, activates endothelial nitric oxide synthase by a phosphatidylinositol-3-OH-kinase-, cAMP-dependent protein kinase-, and Akt-dependent pathway and leads to endothelial-dependent vasorelaxation. J Biol Chem 2004;279:6190-6195.

40. Li PG, Sun L, Han X, Ling S, Gan WT, Xu JW. Quercetin induces rapid eNOS phosphorylation and vasodilation by an Akt-independent and PKA-dependent mechanism. Pharmacology 2012;89:220-228.

41. Si H, Wyeth RP, Liu D. The flavonoid luteolin induces nitric oxide production and arterial relaxation. Eur J Nutr 2014;53:269-275.

42. Rizza S, Muniyappa R, lantorno M, et al. Citrus polyphenol hesperidin stimulates production of nitric oxide in endothelial cells while improving endothelial function and reducing inflammatory markers in patients with metabolic syndrome. J Clin Endocrinol Metab 2011;96:E782-E792.

43. Kim CE, Han S, Kim MH, Kim SW. Flavonoids activate endothelial nitric oxide synthase by altering their phosphorylation via mitogen-activated protein kinase pathways in glucose-induced endothelial cells. J Funct Foods 2015;17:676-684.
44. Khoo NKH, White CR, Pozzo-Miller L, et al. Dietary flavonoid quercetin stimulates vasorelaxation in aortic vessels. Free Radic Biol Med 2010;49:339-347.

45. Ramirez-Sanchez I, Maya L, Ceballos G,Villarreal F. (-)-Epicatechin activation of endothelial cell endothelial nitric oxide synthase, nitric oxide, and related signaling pathways. Hypertension 2010;55:1398-1405.

46. Sánchez M, Galisteo $M$, Vera $R$, et al. Quercetin downregulates NADPH oxidase, increases eNOS activity and prevents endothelial dysfunction in spontaneously hypertensive rats. J Hypertens 2006;24:75-84.

47. Ramirez-Sanchez I, Aguilar H, Ceballos G, Villarreal F. (-)-Epicatechin-induced calcium independent eNOS activation: roles of HSP9O and AKT. Mol Cell Biochem 2012;370:141-150.

48. Wu W, Yang B, Qiao Y, Zhou Q, He H, He M. Kaempferol protects mitochondria and alleviates damages against endothelial toxicity induced by doxorubicin. Biomed Pharmacother 2020;126,110040.

49. Yang D, Yang Z, Chen L, et al. Dihydromyricetin increases endothelial nitric oxide production and inhibits atherosclerosis through microRNA-21 in apolipoprotein E-deficient mice. J Cell Mol Med 2020;124:5911-5925.

50. Kim SW, Cuong TD, Hung TM, Ryoo S, Lee $\mathrm{JH}$, Min BS. Arginase II inhibitory activity of flavonoid compounds from Scutellaria indica. Arch Pharm Res 2013;36, 922-926.

51. Garate-Carrillo A, Navarrete-Yañez V, Ortiz-Vilchis P, etal. Arginase inhibition by (-)-Epicatechin reverses endothelial cell aging. Eur J Pharmacol 2020;885:173442-173442.

52. Iside C, Scafuro M, Nebbioso A, Altucci L. SIRT1 activation by natural phytochemicals: an overview. Front Pharmacol 2020;11.

53. Martínez-Fernández L, Pons Z, Margalef M, Arola-Arnal A, Muguerza B. Regulation of vascular endothelial genes by dietary flavonoids: structure-expression relationship studies and the role of the 
transcription factor KLF-2. J Nutr Biochem 2015;26:277-284.

54. Grassi D, Desideri G, Ferri C. Flavonoids: antioxidants against atherosclerosis. Nutrients 2010;2:889-902.

55. Izzi V, Masuelli L, Tresoldi I, et al. The effects of dietary flavonoids on the regulation of redox inflammatory networks. Front biosci 2012;17:2396-2418.

56. Zhang $T$, Wang $F, X u H X$, et al. Activation of nuclear factor erythroid 2-related factor 2 and PPAR $\gamma$ plays a role in the genistein-mediated attenuation of oxidative stress-induced endothelial cell injury. Br J Nutr 2013; 109:223-235.

57. Yao H., Sun J, Wei J, Zhang X, Chen B, Lin $Y$. Kaempferol protects blood vessels from damage induced by oxidative stress and inflammation in association with the Nrf2/ $\mathrm{HO}-1$ signaling pathway. Front Pharmacol 2020;11:1118-1118.

58. Loh YC, Chan SY, Tew WY, Oo CW, Yam MF. New flavonoid-based compound synthesis strategy for antihypertensive drug development. Life Sci 2020;249,117512.

59. Kim HP, Son KH, Chang HW, Kang SS. Anti-inflammatory plant flavonoids and cellular action mechanisms. J Pharmacol Sci 2004;96:229-245.

60. Polagruto J, Schramm D, Wang-Polagruto J. Lee L, Keen C. Effects of flavonoid-rich beverages on prostacyclin synthesis in humans and human aortic endothelial cells: association with ex vivo platelet function. J Med Food 2003;6:301-308.

61. Jones HS, Gordon A, Magwenzi SG, Naseem K, Atkin SL, Courts FL. The dietary flavonol quercetin ameliorates angiotensin II-induced redox signaling imbalance in a human umbilical vein endothelial cell model of endothelial dysfunction via ablation of p47phox expression. Mol Nutr Food Res 2016;60:787-797.

62. Rezabakhsh A, Rahbarghazi R, Malekinejad H, Fathi F, Montaseri A, Garjani A. Quercetin alleviates high glucose-induced damage on human umbilical vein endothelial cells by promoting autophagy. Phytomed 2019;56:183-193.

63. Lotito, Silvina B., and Balz Frei. Dietary flavonoids attenuate tumor necrosis factor- $\alpha$ induced adhesion molecule expression in human aortic endothelial cells: structure-function relationships and activity after first pass metabolism. J Biol Chem 2006;281(48):37102-37110.

64. Pfaltzgraff ER, Bader, DM. Heterogeneity in vascular smooth muscle cell embryonic origin in relation to adult structure, physiology, and disease. Dev Dyn 2015;244(3):410-416.

65. Morello S, Vellecco V, Alfieri A, Mascolo N, Cicala C. Vasorelaxant effect of the flavonoid galangin on isolated rat thoracic aorta. Life Sci 2006;78:825-830.

66. Fusi F, Spiga O, Trezza A, Sgaragli G, Saponara $\mathrm{S}$. The surge of flavonoids as novel, fine regulators of cardiovascular $\mathrm{Ca}(\mathrm{V})$ channels. Eur J Pharmacol 2017;796:158-174.

67. Novakovic A, Marinko M, Vranic A, et al. Mechanisms underlying the vasorelaxation of human internal mammary artery induced by (-)-epicatechin. Eur J Pharmacol 2015;762:306-312.

68. Fusi F, Trezza A, Tramaglino M, Sgaragli G, Saponara S, Spiga O. The beneficial health effects of flavonoids on the cardiovascular system: focus on $\mathrm{K}+$ channels. Pharmacol Res 2020;152,104625.

69. Tan CS, Yam MF. Mechanism of vasorelaxation induced by 3'-hydroxy-5,6,7,4'-tetramethoxyflavone in the rats aortic ring assay. Naunyn-Schmiedeberg's Arch Pharmacol 2018;391:561-569.

70. Marinko M, Jankovic G, Nenezic D, et al. (-)-Epicatechin-induced relaxation of isolated human saphenous vein: roles of $\mathrm{K}+$ and $\mathrm{Ca}^{2+}$ channels. Phytother Res 2018;2:267-275.

71. Duarte J, Pérez Vizcaíno F, Utrilla $P$, Jiménez J, Tamargo J, Zarzuelo A. Vasodilatory effects of flavonoids in rat aortic smooth muscle: structure-activity relationships. Gen Pharmacol 1993:24:857-862. 
72. Min YS, Yoon HJ, Je HD, et al. Endothelium independent effect of pelargonidin on vasoconstriction in rat aorta. Biomol Ther 2018;26:374-379.

73. Je HD, Kim HD, La HO. The inhibitory effect of apigenin on the agonist-induced regulation of vascular contractility via calcium desensitization-related pathways. Biomol Ther 2014;22:100-105.

74. Orallo F, Camiña M, Álvarez E, Basaran $\mathrm{H}$, Lugnier $\mathrm{C}$. Implication of cyclic nucleotide phosphodiesterase inhibition in the vasorelaxant activity of the citrus-fruits flavonoid ( \pm )-naringenin. Planta Med 2005;71:99-107.

75. Macêdo CL, Vasconcelos LHC, de Correia $A C C$, et al. Mechanisms underlying vasorelaxation induced in rat aorta by galetin 3,6-dimethyl ether, a flavonoid from Piptadenia stipulacea (Benth.) Ducke. Molecules 2014;19:19678-19695.

76. Mahobiya A, Singh TU, Rungsung S, et al. Kaempferol-induces vasorelaxation via endothelium-independent pathways in rat isolated pulmonary artery. Pharmacol Rep 2018;70:863-874.

77. Kumar T, Sharma M, Rana A, et al. Biochanin-A elicits relaxation in coronary artery of goat through different mechanisms. Res Vet Sci 2020;131:206-214.

78. Iozzi D, Schubert R, Kalenchuk VU, et al. Quercetin relaxes rat tail main artery partly via a PKG-mediated stimulation of KCa1.1 channels. Acta Physiologica 2013;208:329-339.

79. Revuelta MP, Hidalgo A, Cantabrana B. Involvement of cAMP and beta-adrenoceptors in the relaxing effect elicited by flavonoids on rat uterine smooth muscle. J Auton Pharmacol 1999;19:353-358.

80. Lacolley P, Regnault V, Nicoletti A, Li Z, Michel JB. The vascular smooth muscle cell in arterial pathology: a cell that can take on multiple roles. Cardiovasc Res 2012;95:194-204.

81. Wu YT, Chen L, Tan ZB, et al. Luteolin inhibits vascular smooth muscle cell prolifer- ation and migration by inhibiting TGFBR1 signaling. Front Pharmacol 2018;9

82. Alcocer F, Whitley D, Salazar-Gonzalez JF, et al. Quercetin inhibits human vascular smooth muscle cell proliferation and migration. Surgery 2002;131:198-204.

83. Shin SS, Ko MC, Noh DH, et al. Morin inhibits PDGF-induced proliferation, migration, and invasion of vascular smooth muscle cells via modulating p27KIP1, AKT, and MMP-9 activities. Gen Physiol Biophys 2018;37:633-645.

84. Shen YJ, Zhu XX, Yang X, et al. Cardamonin inhibits angiotensin II-induced vascular smooth muscle cell proliferation and migration by downregulating p38 MAPK, Akt, and ERK phosphorylation. J Nat Med 2014;68:623-629.

85. Liu R, Heiss EH, Schachner D, Jiang B, Liu W, Breuss JM. Xanthohumol Blocks proliferation and migration of vascular smooth muscle cells in vitro and reduces neointima formation in vivo. J Nat Prod 2017;80:2146-2150.

86. Liu Y, Jia L, Min D, Xu Y, Zhu J, Sun Z. Baicalin inhibits proliferation and promotes apoptosis of vascular smooth muscle cells by regulating the MEG3/p53 pathway following treatment with ox LDL. Int $\mathrm{J}$ Mol Med 2019;43:901-913.

87. Kim K, Kim S, Moh SH, Kang H. Kaempferol inhibits vascular smooth muscle cell migration by modulating BMP-mediated miR-21 expression. Mol Cell Biochem 2015;407:143-149.

88. Kim TJ, Zhang YH, Kim Y, et al. Effects of apigenin on the serum- and platelet derived growth factor-BB-induced proliferation of rat aortic vascular smooth muscle cells. Planta Med 2002;68:605-609.

89. Tsai YC, Leu SY, Peng YJ, et al. Genistein suppresses leptin-induced proliferation and migration of vascular smooth muscle cells and neointima formation. J Cell Mol Med 2017;21:422-431.

90. Xu C, Chen J, Zhang J, et al. Naringenin inhibits angiotensin II-induced vascular 
smooth muscle cells proliferation and migration and decreases neointimal hyperplasia in balloon injured rat carotid arteries through suppressing oxidative stress. Biol Pharm Bull 2013;36:1549-1555

91. Gregg D, Goldschmidt-Clermont PJ. Platelets and cardiovascular disease. Circulation 2003; 108:e88-e90.

92. Estevez B, Du X. New concepts and mechanisms of platelet activation signaling. Physiology 2017;32:162-177.

93. Freedman JE, Parker C, Li L, . Select flavonoids and whole juice from purple grapes inhibit platelet function and enhance nitric oxide release. Circulation 2001;103:2792-2798.

94. Natella F, Nardini M, Belelli F, et al. Effect of coffee drinking on platelets: inhibition of aggregation and phenols incorporation. Br J Nutr 2008;100:1276-1282.

95. Zaragozá C, Monserrat J, Mantecón C, Villaescusa L, Zaragozá F, Álvarez-Mon M. Antiplatelet activity of flavonoid and coumarin drugs. Vascul Pharmacol 2016;87:139-149.

96. Oh WJ, Endale M, Park SC, Cho JY, Rhee $\mathrm{MH}$. Dual roles of quercetin in platelets: phosphoinositide-3-kinase and MAP kinases inhibition, and CAMP-dependent vasodilator-stimulated phosphoprotein stimulation. Evid Based Complement Alternat Med 2012;2012:485262.

97. Bojić M, Debeljak Ž, Tomičić M, MedićŠarić $M$, Tomić S. Evaluation of antiaggregatory activity of flavonoid aglycone series. Nutr J 2011;10:73.

98. Wright B, Spencer JP, Lovegrove JA, Gibbins JM. Flavonoid inhibitory pharmacodynamics on platelet function in physiological environments. Food Funct 2013;4:1803-1810.

99. Stainer $A R$, Sasikumar $P$, Bye $A P$, et al. The metabolites of the dietary flavonoid quercetin possess potent antithrombotic activity, and interact with aspirin to enhance antiplatelet effects. TH Open 2019;3:e244-e258.
100. Ravishankar D, Salamah M, Akimbaev A, et al. Impact of specific functional groups in flavonoids on the modulation of platelet activation. Sci Rep 2018;8:9528.

101. Liu GW, Xie AD, He XW, et al. Antiplatelet activity of chrysin via inhibiting platelet aAiib $\beta 3$-mediated signalling pathway. Mol Nutr Food Res 2016;60(9):1984-93.

102. Guerrero JA, Lozano ML, Castillo J, Benavente-García O, Vicente V, Rivera J. Flavonoids inhibit platelet function through binding to the thromboxane A2 receptor. J Thromb Haemost 2005;3:369-376.

103. Muñoz Y, Garrido A, Valladares L. Equol is more active than soy isoflavone itself to compete for binding to thromboxane A2 receptor in human platelets. Thromb Res 2009;123:740-744.

104. Choi JH, Park SE, Kim SJ, Kim S. Kaempferol inhibits thrombosis and platelet activation. Biochimie 2015;115:177-86.

105. Jin YR, Han XH, Zhang YH, et al. Antiplatelet activity of hesperetin, a bioflavonoid, is mainly mediated by inhibition of PLC-gamma2 phosphorylation and cyclooxygenase-1 activity. Atherosclerosis 2007;194:144-152.

106. Sheu JR, Hsiao G, Chou PH, Shen MY, Chou DS. Mechanisms involved in the antiplatelet activity of rutin, a glycoside of the flavonol quercetin, in human platelets. J Agric Food Chem 2004;52:4414-4418.

107. Gaspar RS, da Silva SA, Stapleton J, et al. Myricetin, the main flavonoid in syzygium cumini leaf, is a novel inhibitor of platelet thiol isomerases PDI and ERp5. Front Pharmacol 2020;10:1678.

108. Stangl VM, Lorenz A, Ludwig N, et al. The flavonoid phloretin suppresses stimulated expression of endothelial adhesion molecules and reduces activation of human platelets. J Nutr 2005;135(2):172-8.

109. Faggio CA, Sureda S, Morabito A, et al. Flavonoids and platelet aggregation: a brief review. Eur J Pharmacol 2017;807:91-101.

110. Münzel T, Camici GG, Maack $C$, Bonetti NR, Fuster V, Kovacic JC. Impact of ox- 
idative stress on the heart and vasculature: part 2 of a 3-part series. J Am Coll Cardiol 2017;70:212-229.

111. Münzel T, Gori T, Bruno RM, Taddei S. Is oxidative stress a therapeutic target in cardiovascular disease? Eur Heart J 2010;31:2741-2748.

112. Suen J, Thomas J, Kranz A, Vun S, Miller $M$. Effect of flavonoids on oxidative stress and inflammation in adults at risk of cardiovascular disease: a systematic review. Healthcare 2016;4(3):69.

113. Procházková $D$, Boušová I, Wilhelmová N. Antioxidant and prooxidant properties of flavonoids. Fitoterapia 2011;82:513-523.

114. Forman HJ, Davies KJ, Ursini F. How do nutritional antioxidants really work: nucleophilic tone and para-hormesis versus free radical scavenging in vivo. Free Radic Biol Med 2014;66:24-35.

115. Kicinska A, Jarmuszkiewicz W. Flavonoids and mitochondria: activation of cytoprotective pathways? Molecules 2020;25:3060.

116. Shiba $Y$, Kinoshita $T$, Chuman $H$, et al. Flavonoids as substrates and inhibitors of myeloperoxidase: molecular actions of aglycone and metabolites. Chem Res Toxicol 2008;21:1600-1609.

117. Al-Numair KS, Chandramohan G, Veeramani C, Alsaif MA. Ameliorative effect of kaempferol, a flavonoid, on oxidative stress in streptozotocin-induced diabetic rats. Redox Rep 2015;20:198-209.

118. Zheng $Y$, Morris A, Sunkara M, Layne J, Toborek M, Hennig B. Epigallocatechin-gallate stimulates NF-E2-related factor and heme oxygenase-1 via caveolin-1 displacement. J Nutr Biochem 2012;23:163-168.

119. Smith RE, Tran K, Smith CC, McDonald M, Shejwalkar P, Hara K. The role of the Nrf2/ARE antioxidant system in preventing cardiovascular diseases. Diseases 2016;4:34.

120. Chekalina N, Burmak $Y$, Petrov $Y$, et al. Quercetin reduces the transcriptional ac- tivity of NF-kB in stable coronary artery disease. Ind Heart J 2018;70:593-597.

121. Choy KW, Murugan D, Leong XF, Abas R, Alias A, Mustafa M.R. Flavonoids as natural anti-inflammatory agents targeting nuclear factor-Kappa $\mathrm{B}(\mathrm{NF \kappa B})$ signaling in cardiovascular diseases: a mini review. Front Pharmacol 2019;10:1295.

122. Van der Heiden K, Cuhlmann S, Luong A, Zakkar M, Evans PC. Role of nuclear factor kappaB in cardiovascular health and disease. Clin Sci 2010;118:593-605.

123. Liu T, Zhang L, Joo D, Sun SC. NF-кB signaling in inflammation. Signal Transduct Target Ther 2017;2:17023.

124. Musunuru K. Atherogenic dyslipidemia: cardiovascular risk and dietary intervention. Lipids 2010;45:907-914.

125. Koshy A. Vijayalakshmi N. Impact of certain flavonoids on lipid profiles - Potential action of Garcinia cambogia flavonoids. Phytother Res 2001;15:395-400.

126. Maron DJ, Lu GP, Cai NS, et al. Cholesterol-lowering effect of a theaflavin-enriched green tea extract: a randomized controlled trial. Arch Intern Med 2003;163:1448-1453.

127. Juźwiak S, Wójcicki J, Mokrzycki K, et al. Effect of quercetin on experimental hyperlipidemia and atherosclerosis in rabbits. Pharmacol Rep 2005;57:604-609.

128. Mariee AD, Abd-Allah GM, El-Beshbishy HA. Protective effect of dietary flavonoid quercetin against lipemic-oxidative hepatic injury in hypercholesterolemic rats. Pharm Biol 2012;50:1019-1025.

129. Jayachitra J, Nalini N. Effect of naringein (citrus flavonoid) on lipid profile in ethanol-induced toxicity in rat. J Food Biochem 2012;36:502-511.

130. Zarzecki MS, Araujo SM, Bortolotto VC, de Paula MT, Jesse CR, Prigol M. Hypolipidemic action of chrysin on triton WR-1339-induced hyperlipidemia in female C57BL/6 mice. Toxicol Rep 2014;1:200-208. 
131. Jung UJ, Cho YY, Choi MS. Apigenin ameliorates dyslipidemia, hepatic steatosis and insulin resistance by modulating metabolic and transcriptional profiles in the liver of high-fat diet-induced obese mice. Nutrients 2016;8(5):305.

132. Imran A, Butt MS, Arshad MS, et al. Exploring the potential of black tea based flavonoids against hyperlipidemia related disorders. Lipids Health Dis 2018;17:57-57.

133. Miyake Y, Suzuki E, Ohya S, et al. Lipid-lowering effect of eriocitrin, the main flavonoid in lemon fruit, in rats on a highfat and high-cholesterol diet. J Food Sci 2006;71:S633-S637.

134. Li Y, Wu S. Epigallocatechin gallate suppresses hepatic cholesterol synthesis by targeting SREBP-2 through SIRT1/ FOXO1 signaling pathway. Mol Cell Biochem 2018;448(1-2):175-185.

135. Manzoni AG, Passos DF, da Silva JLG, et al. Rutin and curcumin reduce inflammation, triglyceride levels and ADA activity in serum and immune cells in a model of hyperlipidemia. Blood Cells Mol Dis 2019;76:13-2

136. Lee $\mathrm{KH}$, Park $E$, Lee $H J$, et al. Effects of daily quercetin-rich supplementation on cardiometabolic risks in male smokers. Nutr Res Pract 2011;5:28-33.

137. Pfeuffer $M$, Auinger $A$, Bley $U$, et al. Effect of quercetin on traits of the metabolic syndrome, endothelial function and inflammation in men with different APOE isoforms. Nutr Metab Cardiovasc Dis 2013;23:403-409.

138. Sahebkar A. Effects of quercetin supplementation on lipid profile: a systematic review and meta-analysis of randomized controlled trials. Crit Rev Food Sci Nutr 2015,57.

139. Zhang M, Zongkai X, Gao W, Pu L, Wei J, Guo,C. Quercetin regulates hepatic cholesterol metabolism by promoting cholesterol-to-bile acid conversion and cholesterol efflux in rats. Nutr Res 2016;36(3):271-279.
140. Fuchs FD, Whelton PK. High blood pressure and cardiovascular disease. Hypertension 2020;75:285-292.

141. Clark JL, Zahradka P, Taylor CG. Efficacy of flavonoids in the management of high blood pressure. Nutr Rev 2015;73:799-822.

142. Duarte J, Pérez-Palencia R, Vargas F, et al. Antihypertensive effects of the flavonoid quercetin in spontaneously hypertensive rats. Br J Pharmacol 2001;133:117-124.

143. Olaleye M, Crown O, Akinmoladun A, Akindahunsi $A$. Rutin and quercetin show greater efficacy than nifedipin in ameliorating hemodynamic, redox, and metabolite imbalances in sodium chloride-induced hypertensive rats. Hum Exp Toxicol 2014;33:602-608.

144. Galindo P, Rodriguez-Gómez I, GonzálezManzano S, et al. Glucuronidated quercetin lowers blood pressure in spontaneously hypertensive rats via deconjugation. Plos One 2012;7,e32673.

145. Ramanathan V, Rajagopal S. Chrysin ameliorates the lipid profiles in $\mathrm{N} \omega$-nitro-l-arginine-methylester-induced hypertensive rats. Am J Biochem Mol Biol 2016;6:60-66.

146. Villar I, Jiménez R, Galisteo M, Garcia-Saura M, Zarzuelo A, Duarte J. Effects of chronic chrysin treatment in spontaneously hypertensive rats. Planta Medica 2002;68:847-850.

147. Jaffri JM, Mohamed S, Rohimi N, Ahmad IN, Noordin MM, Manap YA. Antihypertensive and cardiovascular effects of catechin-rich oil palm (Elaeis guineensis) leaf extract in nitric oxide-deficient rats. J Med Food 2011;14:775-783.

148. Luo D, Xu J, Chen $X$, et al. (-)-Epigallocatechin-3-gallate (EGCG) attenuates salt-induced hypertension and renal injury in Dahl salt-sensitive rats. Sci Rep 2020;10:4783.

149. Hashemzaei M, Rezaee R, Nabatzehi $M$, et al. Anti-hypertensive effect of crocin and hesperidin combination in 
high-fat diet treated rats. Exp Ther Med 2020;19:3840-3844.

150. Oyagbemi AA, Omobowale TO, Adejumobi OA, Owolabi AM, Ogunpolu BS, Falayi OO. Antihypertensive power of naringenin is mediated via attenuation of mineralocorticoid receptor (MCR)/ angiotensin converting enzyme (ACE)/ kidney injury molecule (Kim1) signaling pathway. Eur J Pharmacol 2020;880:173142.

151. Conquer JA, Maiani G, Azzini E, Raguzzini A, Holub BJ. Supplementation with quercetin markedly increases plasma quercetin concentration without effect on selected risk factors for heart disease in healthy subjects. J Nutr 1998;128:593-597.

152. Javadi F, Eghtesadi S, Ahmadzadeh A, et al. The effect of quercetin on plasma oxidative status, C-reactive protein and blood pressure in women with rheumatoid arthritis. Int J Prev Med 2014;5: 293-301.

153. Zahedi M, Ghiasvand R, Feizi A, Asgari G, Darvish L. Does quercetin improve cardiovascular risk factors and inflammatory biomarkers in women with type 2 diabetes: a double-blind randomized controlled clinical trial. Int J Prev Med 2013;4:777-785.

154. Edwards RL, Lyon T, Litwin SE, Rabovsky A, Symons JD, Jalili T. Quercetin reduces blood pressure in hypertensive subjects. J Nutr 2007;137:2405-2411.

155. Egert S, Bosy-Westphal A, Seiberl J, et al. Quercetin reduces systolic blood pressure and plasma oxidised low-density lipoprotein concentrations in overweight subjects with a high-cardiovascular disease risk phenotype: a double-blinded, placebo-controlled cross-over study. $\mathrm{Br} \mathrm{J}$ Nutr 2009;102:1065-1074.

156. Serban MC, Sahebkar A, Zanchetti A, et al. Effects of quercetin on blood pressure: a systematic review and meta-analysis of randomized controlled trials. J Am Heart Assoc 2016;5:002713.
157. Bondonno NP, Bondonno $C P$, Rich $L$, et al. Acute effects of quercetin-3-O-glucoside on endothelial function and blood pressure: a randomized dose-response study. Am J Clin Nutr 2016;104:97-103.

158. Reshef N, Hayari Y, Goren C, Boaz M, Madar Z, Knobler H. Antihypertensive effect of sweetie fruit in patients with stage I hypertension. Am J Hypertens 2005;18:1360-1363.

159. Valls RM, Pedret $A$, Calderón-Pérez $L$, et al. Effects of hesperidin in orange juice on blood and pulse pressures in mildly hypertensive individuals: a randomized controlled trial (Citrus study). Eur J Nutr 2020;60(3):1277-1288

160. Maaliki DAA, Shaito GP, El-Yazbi, A, Eid, $\mathrm{AH}$. Flavonoids in hypertension: a brief review of the underlying mechanisms. Curr Opin Pharmacol 2019;45:57-65.

161. Carbone S, Canada JM, Billingsley HE, Siddiqui MS, Elagizi A, Lavie CJ. Obesity paradox in cardiovascular disease: where do we stand? Vasc Health Risk Manag 2019;15:89-100.

162. Lajous M, Rossignol E, Fagherazzi G, Perquier F, Scalbert A, Clavel-Chapelon F, Boutron-Ruault MC. Flavonoid intake and incident hypertension in women. Am J Clin Nutr 2016;103(4):1091-8.

163. Ottaviani JI, Britten A, Lucarelli D, et al. Biomarker-estimated flavan-3-ol intake is associated with lower blood pressure in cross-sectional analysis in EPIC Norfolk. Sci Rep 2020;10:17964.

164. Rufino AT, Costa VM, Carvalho F, Fernandes E. Flavonoids as antiobesity agents: a review. Med Res Rev 2021;41:556-585.

165. Akhlaghi, M., Ghobadi, S., Mohammad Hosseini, M., Gholami, Z., Mohammadian F. Flavanols are potential anti-obesity agents, a systematic review and meta-analysis of controlled clinical trials. Nutr Metab Cardiovasc Dis 2018;28:675-690.

166. Lee YJ, Seo MJ, Lee OH, Kim KJ, Lee BY. Hesperetin inhibits lipid accumulation 
and ros production during adipocyte differentiation in 3t3-L1 cells. J Food Biochem 2017;41(3):e12348.

167. Torres-Villarreal D, Camacho A, Castro H, Ortiz-Lopez R, de la Garza AL. Anti-obesity effects of kaempferol by inhibiting adipogenesis and increasing lipolysis in 3T3-L1 cells. J Physiol Biochem 2019;75:83-88.

168. Seo MJ, Lee YJ, Hwang JH, Kim KJ, Lee BY. The inhibitory effects of quercetin on obesity and obesity-induced inflammation by regulation of MAPK signaling. J Nutr Biochem 2015;26:1308-1316.

169. Choi JH,Yun JW. Chrysin induces brown fat-like phenotype and enhances lipid metabolism in 3T3-L1 adipocytes. Nutrition 2016;32:1002-1010.

170. Gómez-Zorita S, Lasa A, Abendaño N, et al. Phenolic compounds apigenin, hesperidin and kaempferol reduce in vitro lipid accumulation in human adipocytes. J Transl Med 2017;15:237.

171. Su H, Feng L, Zheng X, Chen W. Myricetin protects against diet-induced obesity and ameliorates oxidative stress in C57BL/6 mice. J Zhejiang Univ Sci B 2016;17:437-446.

172. Kumar S, Alagawadi KR. Anti-obesity effects of galangin, a pancreatic lipase inhibitor in cafeteria diet fed female rats. Pharm Biol 2013;51:607-613.

173. Pai SA, Martis EA, Munshi RP, Gursahani MS, Mestry SN, Juvekar AR. Chrysin mitigated obesity by regulating energy intake and expenditure in rats. J Trad Complement Med 2020;10:577-585.

174. Su T, Huang $C$, Yang $C$, et al. Apigenin inhibits STAT3/CD36 signaling axis and reduces visceral obesity. Pharmacol Res 2020;152:104586.

175. Llaneza $P$, González $C$, Fernández-lñarrea J, Alonso A, Díaz F, Pérez-López, FR. Soy isoflavones improve insulin sensitivity without changing serum leptin among postmenopausal women. Climacteric 2012;15:611-620.
176. Myoung HJ, Kim G, Nam KW. Apigenin isolated from the seeds of Perilla frutescens britton var crispa (Benth.) inhibits food intake in C57BL/6J mice. Arch Pharm Res 2010;33:1741-1746.

177. Rahim A, Takahashi Y, Yamaki K. Mode of pancreatic lipase inhibition activity in vitro by some flavonoids and non-flavonoid polyphenols. Food Res Int 2015;75:289-294.

178. Martinez-Gonzalez Al, Díaz-Sánchez ÁG, Rosa LA, Bustos-Jaimes I, Alvarez-Parrilla E. Inhibition of $\alpha$-amylase by flavonoids: structure activity relationship (SAR). Spectrochim Acta A Mol Biomol Spectrosc 2019;206:437-447.

179. Hua F, Zhou P, Wu HY, Chu GX, Xie ZW, Bao $\mathrm{GH}$. Inhibition of $\alpha$-glucosidase and $\alpha$-amylase by flavonoid glycosides from Lu'an GuaPian tea: molecular docking and interaction mechanism. Food Funct 2018;9:4173-4183.

180. Seo S, Lee M, Chang E, Shin Y, Oh S, $\mathrm{Kim} I \mathrm{H}$, et al. Rutin increases muscle mitochondrial biogenesis with AMPK activation in high-fat diet-induced obese rats. Nutrients 2017;7:8152-8169.

181. Han Y, Wu J, Shen J, Chen L, He T, Jin M., et al. Pentamethylquercetin induces adipose browning and exerts beneficial effects in 3T3-L1 adipocytes and high-fat diet-fed mice. Sci Rep 2017;7:1123.

182. Choi H, Kim C, Yu R. Quercetin upregulates uncoupling protein 1 in white/ brown adipose tissues through sympathetic stimulation. J Obes Metab Syndr 2018;27:102-109.

183. Zhang $X$, Li $X$, Fang $H$, et al. Flavonoids as inducers of white adipose tissue browning and thermogenesis: signaling pathways and molecular triggers. Nutr Metab 2019;16:47.

184. Bai $Y$, Wang S, Wang $X$, et al. The flavonoid-rich Quzhou Fructus Aurantii extract modulates gut microbiota and prevents obesity in high-fat diet-fed mice. Nutr Diabetes 2019;9,30. 
185. Gil-Cardoso K, Ginés I, Pinent M, Ardévol A, Blay M, Terra X. Effects of flavonoids on intestinal inflammation, barrier integrity and changes in gut microbiota during diet-induced obesity. Nutr Res Rev 2016;29:234-248.

186. Leon BM, Maddox TM. Diabetes and cardiovascular disease: epidemiology, biological mechanisms, treatment recommendations and future research. World $\mathrm{J}$ Diabetes 2015;6:1246-1258.

187. Russo B, Picconi F, Malandrucco I, Frontoni S. Flavonoids and insulin-resistance: from molecular evidences to clinical trials. Int J Mol Sci 2019;20:2061.

188. Jain D, Bansal MK, Dalvi R, Upganlawar A, Somani R. Protective effect of diosmin against diabetic neuropathy in experimental rats. J Integr Med 2014;12:35-41.

189. Malik S, Suchal K, Khan SI, et al. Apigenin ameliorates streptozotocin-induced diabetic nephropathy in rats via MAPK-NF$\kappa B-T N F-\alpha$ and TGF- $\beta 1-M A P K-$ fibronectin pathways. Am J Physiol Renal Physiol 2017;313:F414-F422.

190. Shi GJ, Li Y, Cao QH, et al. In vitro and in vivo evidence that quercetin protects against diabetes and its complications: A systematic review of the literature. Biomed Pharmacother 2019;109:1085-1099.

191. Jiang B, Geng Q, Li T, Mohammad Firdous S, Zhou X. Morin attenuates STZ-induced diabetic retinopathy in experimental animals. Saudi J Biol Sci 2020;27:2139-2142.

192. Jayaraman R, Subramani S, Sheik Abdullah SH, Udaiyar M. Antihyperglycemic effect of hesperetin, a citrus flavonoid, extenuates hyperglycemia and exploring the potential role in antioxidant and antihyperlipidemic in streptozotocin-induced diabetic rats. Biomed Pharmacother 2018;97:98-106.

193. Chandramohan G, Al-Numair KS, Alsaif MA, Veeramani $C$. Antidiabetic effect of kaempferol a flavonoid compound, on streptozotocin-induced diabetic rats with special reference to glycoprotein components. Prog Nutr 2014;17:50-57.

194. Nettleton JA, Harnack LJ, Scrafford CG, Mink PJ, Barraj LM, Jacobs DR. Dietary flavonoids and flavonoid-rich foods are not associated with risk of type 2 diabetes in postmenopausal women. J Nutr 2006;136:3039-3045.

195. Zamora-Ros R, Forouhi NG, Sharp SJ, et al. Dietary intakes of individual flavanols and flavonols are inversely associated with incident type 2 diabetes in European populations. J Nutr 2014;144:335-343.

196. Yao Z, Gu Y, Zhang Q, et al. Estimated daily quercetin intake and association with the prevalence of type 2 diabetes mellitus in Chinese adults. Eur $\mathrm{J}$ Nutr 2019;58:819-830.

197. Song Y, Manson JE, Buring JE, Sesso HD, Liu S. Associations of dietary flavonoids with risk of type 2 diabetes, and markers of insulin resistance and systemic inflammation in women: a prospective study and cross-sectional analysis. J Am Coll Nutr 2005;24:376-384.

198. Jennings A, Welch, AA, Spector T, Macgregor A, Cassidy A. Intakes of anthocyanins and flavones are associated with biomarkers of insulin resistance and inflammation in women. J Nutr 2014;144:202-208.

199. Wedick NM, Pan A, Cassidy A, et al. Dietary flavonoid intakes and risk of type 2 diabetes in US men and women. Am J Clin Nutr 2012;95:925-933.

200. Liu YJ, Zhan J, Liu XL, Wang Y, Ji J, He QQ. Dietary flavonoids intake and risk of type 2 diabetes: a meta-analysis of prospective cohort studies. Clin Nutr 2014;33:59-63.

201. Guo XF, Ruan Y, Li ZH, Li D. Flavonoid subclasses and type 2 diabetes mellitus risk: a meta-analysis of prospective cohort studies. Crit Rev Food Sci Nutr 2019;59:2850-2862. 
202. Huxley R, Lee CM, Barzi F, et al. Coffee, decaffeinated coffee, and tea consumption in relation to incident type 2 diabetes mellitus: a systematic review with meta-analysis. Arch Intern Med 2009;169:2053-2063.

203. van Woudenbergh, GJ, Kuijsten A, Drogan $D$, et al. Tea consumption and incidence of type 2 diabetes in Europe: the EPIC-InterAct case-cohort study. PLOS ONE 2012;7:30.

204. Yang WS, Wang WY, Fan WY, Deng Q, Wang $X$. Tea consumption and risk of type 2 diabetes: a dose-response meta-analysis of cohort studies. Br J Nutr 2014;111:1329-1339.

205. Al-Ishaq RK, Abotaleb M, Kubatka P, Kajo $K$, Büsselberg D. Flavonoids and their anti-diabetic effects: cellular mechanisms and effects to improve blood sugar levels. Biomolecules 2019;9:430.

206. Chen J, Mangelinckx S, Adams A, Wang Z, Li W, De Kimpe N. Natural flavonoids as potential herbal medication for the treatment of diabetes mellitus and its complications. Nat prod commun 2015;10(1):1934578X1501000140.

207. Mahmoud A, Ahmed O, Ashour M, Abdel Moneim A. In vivo and in vitro antidiabetic effects of citrus flavonoids; a study on the mechanism of action. Int J Diabetes Dev Ctries 2015;35:250-263.

208. Frostegård J. Immunity, atherosclerosis and cardiovascular disease. BMC Medicine 2013;11:117.

209. Salvamani S, Gunasekaran B, Shaharuddin NA, Ahmad SA, Shukor MY. Antiartherosclerotic effects of plant flavonoids. Biomed Res Int 2014;480258.

210. Cao, H, Jia Q, Yan L, Chen C, Xing S, Shen D. Quercetin suppresses the progression of atherosclerosis by regulating MST1-mediated autophagy in ox-LDLinduced RAW264.7 macrophage foam cells. Int J Mol Sci 2019;20:6093.

211. Ren K, Jiang T, Zhou HF, Liang Y, Zhao, GJ. Apigenin retards atherogenesis by promoting $A B C A 1-m e d i a t e d$ cholesterol efflux and suppressing inflammation. Cell Physiol Biochem 2018;47:2170-2184.

212. Yan L, Jia Q, Cao H, et al. Fisetin ameliorates atherosclerosis by regulating PCSK9 and LOX 1 in apoE ${ }^{-/-}$mice. Exp Ther Med $2021 ; 21: 25$.

213. Kong L, Luo C, Li X, Zhou Y, He H. The anti-inflammatory effect of kaempferol on early atherosclerosis in high cholesterol fed rabbits. Lipids Health Dis 2013;12:115.

214. Reis JP, Loria CM, Steffen LM, et al. Coffee, decaffeinated coffee, caffeine, and tea consumption in young adulthood and atherosclerosis later in life. Arterioscler Thromb Vasc Biol 2010;30:2059-2066.

215. Dalgaard F, Bondonno NP, Murray K, et al. Associations between habitual flavonoid intake and hospital admissions for atherosclerotic cardiovascular disease: a prospective cohort study. Lancet Planet Health 2019;3:e450-e459.

216. Sun L, Li E, Wang F, et al. Quercetin increases macrophage cholesterol efflux to inhibit foam cell formation through activating PPAR $\gamma$-ABCA1 pathway. Int J Clin Exp Pathol 2015;8:10854-10860.

217. Li S, Cao H, Shen D, Jia Q, Chen C, Xing $S L$. Quercetin protects against ox LDL induced injury via regulation of ABCAI, LXR $\alpha$ and PCSK9 in RAW264.7 macrophages. Mol Med Rep 2018;18:799-806.

218. Wang S, Zhang $X$, Liu M, et al. Chrysin inhibits foam cell formation through promoting cholesterol efflux from RAW264.7 macrophages. Pharm Biol 2015;53:1481-1487.

219. He XW, Yu D, Li WL, et al. Anti-atherosclerotic potential of baicalin mediated by promoting cholesterol efflux from macrophages via the PPAR $\gamma-L X R \alpha-A B-$ CA1/ABCG1 pathway. Biomed Pharmacother 2016;83:257-264.

220. Li XY, Kong LX, Li J, He HX, Zhou YD. Kaempferol suppresses lipid accumulation in macrophages through the downregulation of cluster of differentiation 36 
and the upregulation of scavenger receptor class B type I and ATP-binding cassette transporters $A 1$ and $\mathrm{G} 1$. Int $\mathrm{J}$ Mol Med 2013;31:331-338.

221. Jia $Q$, Cao H, Shen D, Yan L, Chen C, Xing S. Fisetin, via CKIP-1/REG $\gamma$, limits oxidized LDL-induced lipid accumulation and senescence in RAW264.7 macrophage-derived foam cells. Eur J Pharmacol 2019;865:23.

222. Deng $Q$, Li XX, Fang Y, Chen X, Xue J. Therapeutic potential of quercetin as an antiatherosclerotic agent in atherosclerotic cardiovascular disease: a review. Evid Based Complement Alternat Med 2020;5926381.
223. Jiang $Y H$, Jiang $L Y$, Wang $Y C, M a D F, L i$ $X$. Quercetin attenuates atherosclerosis via modulating oxidized LDL-induced endothelial cellular senescence. Front Pharmacol 2020;11.

224. Cao H, Jia Q, Shen D, Yan L, Chen C, Xing S. Quercetin has a protective effect on atherosclerosis via enhancement of autophagy in $\mathrm{ApoE}(-/-)$ mice. Exp Ther Med 2019;18:2451-2458.

225. Song $L, X u$ M, Lopes-Virella MF, Huang Y. Quercetin inhibits matrix metalloproteinase-1 expression in human vascular endothelial cells through extracellular signal-regulated kinase. Arch Biochem Biophys 2001;391:72-78. 